\title{
Review on III-V Semiconductor Single Nanowire-Based Room Temperature Infrared Photodetectors
}

\author{
Ziyuan Li ${ }^{1}$, Jeffery Allen ${ }^{2}$, Monica Allen ${ }^{2}$, Hark Hoe Tan ${ }^{1,3}$, Chennupati Jagadish ${ }^{1,3}$ and \\ Lan Fu 1,3,*(D) \\ 1 Department of Electronic Materials Engineering, Research School of Physics, The Australian National \\ University, Canberra, ACT 2601, Australia; ziyuan.li@anu.edu.au (Z.L.); Hoe.Tan@anu.edu.au (H.H.T.); \\ Chennupati.Jagadish@anu.edu.au (C.J.) \\ 2 Air Force Research Laboratory, Munitions Directorate, Eglin AFB, FL 32542, USA; \\ jeffery.allen.12@us.af.mil (J.A.); monica.allen.3@us.af.mil (M.A.) \\ 3 Australian Research Council Centre of Excellence for Transformative Meta-Optical Systems, \\ Department of Electronic Materials Engineering, Research School of Physics, The Australian National \\ University, Canberra, ACT 2601, Australia \\ * Correspondence: lan.fu@anu.edu.au
}

Received: 10 February 2020; Accepted: 17 March 2020; Published: 19 March 2020

\begin{abstract}
Recently, III-V semiconductor nanowires have been widely explored as promising candidates for high-performance photodetectors due to their one-dimensional morphology, direct and tunable bandgap, as well as unique optical and electrical properties. Here, the recent development of III-V semiconductor-based single nanowire photodetectors for infrared photodetection is reviewed and compared, including material synthesis, representative types (under different operation principles and novel concepts), and device performance, as well as their challenges and future perspectives.
\end{abstract}

Keywords: III-V semiconductor; nanowire; infrared photodetector

\section{Introduction}

In the last decades, there has been an increased demand for semiconductor infrared (IR) photodetectors, due to their broad defense and civilian applications such as imaging, night vision, free space optical communication, search and rescue, surveillance, missile tracking, material inspection and identification, scientific instrumentation (e.g., spectroscopy), and astronomy [1,2]. For example, the current state-of-the-art infrared photodetector technology in the market has been mainly based on the planar semiconductor detectors such as $\mathrm{Si}(0.4-1.1 \mu \mathrm{m})$, InGaAs $(1.1-1.7 \mu \mathrm{m})$, Ge $(0.7-1.8 \mu \mathrm{m})$, InAs $(0.9-3.5 \mu \mathrm{m})$, and $\mathrm{HgCdTe}(2-10.6 \mu \mathrm{m})$. Although most of these detectors have been explored for decades with mature industrial platforms, limited spectral range, low responsivity, and high noise level at room temperature have limited their use in many practical applications. In particular, in narrow bandgap materials such as InAs [3], InSb [4,5], InAsSb [6], and HgCdTe [7] with extended detection wavelength from near- and short-wavelength infrared (NIR and SWIR) to mid-wavelength infrared (MWIR) and beyond, the detectivity degrades significantly at longer wavelengths due to increased dark current resulting from carrier generation-recombination and minority carrier diffusion [8]. In the planar photodetector device design, a common compromise that is often made is to reduce absorption volume to suppress the dark current while sacrificing some responsivity. Leveraging the development of nanotechnology, many nanostructures, such as nanowires (NWs) [9-11], nanotubes [12-14], nanopillars [15-17], nanorods [18-20], and two-dimensional (2D) materials [21-23], have emerged in the pursuit of high-performance room-temperature photodetectors, as their nanoscale 
size offers extremely small active volume (for reduced dark current) and at the same time, distinct light absorption properties for large responsivity, as well as shorter response time and larger bandwidth [24].

One-dimensional (1D) semiconductor nanowires have attracted significant attention as the promising candidates for the next generation nanoscale optoelectronic devices such as photodetectors [9-11], solar cells [25-27], light-emitting diodes (LEDs) [28], and lasers [29-31]. These devices have unique geometry and physical properties leading to excellent optical and electrical properties; quantum size effects; as well as enhanced light, biological, or chemical sensitivity [32,33]. In particular, III-V semiconductor nanowires have direct and widely tunable bandgap, high absorption coefficient and carrier mobility, as well as flexibility to form heterostructures, making them excellent candidates for photodetection [1,33]. Moreover, it is found that the enhanced photocarrier lifetime and decreased transit time in nanowire detectors lead to much higher gain in nanowires in comparison to bulk structures [34]. Researchers have also implemented transistor structures [11,35-37], metal-semiconductor (M-S) or metal-semiconductor-metal (M-S-M) Schottky junctions [38-41], p-n junctions [42,43], and heterostructures [42-46] in nanowire-based photodetectors to further reduce dark current and enhance $I_{\text {light }} / I_{\text {dark }}$ ratio for infrared photodetection. In addition, surface passivation $[11,36,44]$ and introduction of the photo-gating effect $[36,37,47]$ have been carried out to manipulate the surface states of the nanowire materials to further enhance their performance. It has also been demonstrated that metal-cluster decoration [11] and nanoantenna structures [48] are capable of localizing and enhancing the spectral selectivity and light absorption of nanowires by coupling of strongly resonant and highly localized plasmonic modes.

For practical applications, ensemble nanowire array photodetectors are important. However, single nanowire-based devices provide a much simpler platform for fundamental study without having to consider complex effects such as optical coupling of surrounding nanowires as well as nonuniformity effects that arise from nanowire growth and contact formation processes in ensemble devices [33]. Here, the recent development of III-V semiconductor nanowire infrared photodetectors operating at room temperature is reviewed with an emphasis on single nanowire-based photodetectors. This includes nanowire synthesis approaches and mechanisms, typical device structures and performance, as well as the current challenges and some strategies for development toward high performance future applications.

\section{Nanowires Synthesis}

III-V semiconductor nanowires can be either synthesized by top-down or bottom-up approaches, or a combination of both $[33,49,50]$. In the top-down method, nanowire structures are obtained through direct writing or wet/dry etching of lithographically-defined patterns on a bulk substrate or layered structure. Nanolithography techniques can be used to form ordered nanowire arrays with accurately defined placement, size, spacing, and orientation [33,49]. However, top-down methods do not offer the important advantages of material saving and flexibility in material/structure design benefiting from the effective strain relaxation as offered by bottom-up nanowire synthesis methods. Additionally, the etching process can introduce surface defects and roughness on the sidewall that adversely affect the nanowire properties and lead to degraded device performance [33,51]. Therefore, top-down approaches are rarely used for single nanowire photodetectors and have been thoroughly reviewed [33]. In this review, we mainly focus on the discussion on bottom-up approaches.

In the bottom-up method, freestanding nanowires are grown anisotropically on a substrate along the axial direction by employing their constituent atoms. Several techniques $[33,50]$ have been explored for nanowire growth. These include metal organic [44,52] or solid-source [53] chemical vapor deposition (CVD), molecular beam epitaxy (MBE) [54], and energy transfer method such as pulsed laser ablation [55]. The bottom-up method is especially promising for future highly-integrated electronic and optical systems as high-quality nanowire growth has been demonstrated on various substrates [56,57]. 
The bottom-up nanowires are normally synthesized via catalyst assisted vapor-liquid-solid (VLS) $[9,44,58]$ and/or vapor-solid-solid (VSS) [59] growth mechanisms. The catalyst can be either disparate metals such as Au nanoparticles (foreign metal-catalyzed growth) [9,44] or particles that contain constituent elements of the nanowire (self-catalyzed growth) [60]. Normally such nanowire ensembles have no ordering unless a mask is used to arrange the seed particles [56]. Site-controlled VLS growth has also been used to grow planar nanowires [61].

Non-catalyzed growth techniques, such as selective area epitaxy (SAE) [62,63], are also often used to form nanowires on a prepatterned substrate, to accurately define position, geometry, and uniformity of the nanowire arrays [33]. Oxide-assisted growth (OAG) [64] is another mechanism that is used to grow nanowires. In this method, the semiconductor and its oxide are adsorbed on the substrate surface and the semiconductor atoms create nucleation centers, which then assist the formation of the semiconductor nanowires. The oxide acts as a passivating shell that suppresses the crystal growth in the lateral direction [64]. Some research has also examined the use of template-assisted (TA) mechanisms that employ a prefabricated template such as anodic aluminum oxide (AAO) [65] membrane to control the nanowire diameter [50].

\section{Single Nanowire Photodetectors}

Due to their distinct geometry, single nanowire devices can be fabricated into two different device configurations: (i) horizontal configuration where the nanowires are transferred from free standing positions to lying on another substrate horizontally on their growth axes, and (ii) vertical configuration, where the nanowire is perpendicular to the substrate. These different configurations lead to different absorption properties [33,50] and variation in the fabrication techniques [33]. In the horizontal configuration, light is illuminated onto the nanowire in a perpendicular direction to its axis, whereas in the vertical configuration, the direction of incident light is parallel to the nanowire axis. Vertical nanowire devices have a much larger absorption cross section compared with their physical cross section, and thus a larger absorption efficiency [25]. Single vertical nanowire photodetectors, however, have been rarely reported $[43,66]$, which could be due to practical considerations and challenges for material growth and device fabrication. In comparison, single horizontal nanowire photodetectors are more commonly implemented and characterized and have been reported widely in many material systems. In this section, typical III-V single nanowire infrared photodetectors are discussed based on their device structures and operating wavelengths. The associated performance metrics such as responsivity $(R)$, specific detectivity $\left(D^{*}\right)$, gain $(G)$, external quantum efficiency $(E Q E)$, and response time $(t)[1,34]$ under room temperature are summarized and compared in Table 1.

\subsection{Photoconductors}

One of the simplest forms of photodetectors are photoconductors that produce current under an optical excitation when an external bias is applied. The current increases with the light illumination, exceeding dark current, and thus provides the light-detection ability. The geometry and nanoscale dimensions of nanowire photoconductors enable enhanced light absorption, polarization sensitivity, and internal photoconductive gain compared to bulk photoconductors $[48,67,68]$. For example, similar to bulk/planar devices, light at different wavelengths can be detected using nanowires based on different materials. Yang et al. demonstrated a single-nanowire spectrometer based on a compositionally engineered semiconducting $\mathrm{CdS}_{x} \mathrm{Se}_{1-x}$ nanowires [69]. It could reconstruct incident spectra by measuring photocurrents along the nanowire axis, indicating that single nanowire devices are potential candidates as ultracompact microspectrometers for accurate and broadband light reconstruction, as well as high-resolution spectral imaging [69]. It has also been shown that the light absorption in Ge nanowires can be spectrally tuned and enhanced by engineering their size, geometry, and orientation as the incident light can be efficiently coupled to strong resonant modes supported in such subwavelength, high refractive index semiconductor nanostructures [70]. Moreover, some III-V nanowires, such as 
GaAs [71] and InP [72], show ultrafast photocarrier dynamics, indicating their potential application as high-speed photodetectors.

Among III-V nanowire photoconductors, narrow bandgap binary nanowire materials, such as InAs [11], GaSb [73], and InSb [74], can provide broadband photodetection spanning from visible (VIS) to IR regions. InAs nanowires have been demonstrated to have high carrier mobility, easy formation of ohmic contact, as well as excellent optoelectronic properties [11]. Miao et al. reported a single InAs nanowire near-infrared photodetector with a detection wavelength up to $\sim 1.5 \mu \mathrm{m}$ and photocurrent responsivity as high as $1.9 \times 10^{3} \mathrm{~A} / \mathrm{W}$ [11]. The carrier mobility and photoresponsivity could be further enhanced by addition of an $\mathrm{Al}_{2} \mathrm{O}_{3}$ or $\mathrm{HfO}_{2}$ passivation layer that can suppress the negative influence of surface defect states and atmospheric molecules [11]. Yuan et al. showed that nanowire photodetector responsivity can also be enhanced using in situ passivation by epitaxial growth of a GaInP shell on GaAs core nanowires [75], whereas Li et al. demonstrated enhanced infrared photoresponse of GaAsSb nanowires by the in situ passivation of adding an InP shell [76]. Moreover, core-shell heterostructures, such as InAs/AlSb core-shell [46], form a type-II bandgap alignment that further improves charge carrier separation, photosensivity, and photoresponse. Single GaSb nanowire photodetectors have also been fabricated on rigid $\mathrm{SiO}_{2} / \mathrm{Si}$ and flexible polyethylene terephthalate (PET) substrates with high responsivity and fast response coupled with stable photoswitching in a broad spectral range from ultraviolet (UV) to NIR [73].

Ternary III-V nanowires with tunable bandgaps, such as GaAsSb [9], InGaAs [77], and InAsP [78], have been also extensively studied. $\mathrm{Li}$ et al. demonstrated a single $\mathrm{GaAs}_{0.56} \mathrm{Sb}_{0.44}$ nanowire photodetector with good responsivity and detectivity at a low operating bias voltage of $0.15 \mathrm{~V}$ at both 1.3 and $1.55 \mu \mathrm{m}$ telecommunication wavelengths by tuning the bandgap of GaAsSb (Figure 1) [9]. InGaAs nanowires have also been reported as room temperature high-performance NIR photodetectors with high responsivity of $6.5 \times 10^{3} \mathrm{~A} / \mathrm{W}$ and $E Q E$ of $5.04 \times 10^{5 \%}$ [77]. Ren et al. synthesized $\operatorname{InAs} x \mathrm{P}_{1-x}$ $(0 \leq x \leq 1)$ nanowires that span the whole range of $x$ and studied their photoresponse in the broad IR range from 0.7 to $3.5 \mu \mathrm{m}$ [78]. A responsivity of $5.417 \times 10^{3} \mathrm{~A} / \mathrm{W}$ and $E Q E$ of $3.96 \times 10^{5} \%$ at $1.7 \mu \mathrm{m}$ and $0.5 \mathrm{~V}$ were demonstrated for $\operatorname{InAs_{0.52}} \mathrm{P}_{0.48}$ [78]. It was also found that the ternary $\operatorname{InAs} x_{x} \mathrm{P}_{1-x}$ nanowire detectors showed better performance than binary $\mathrm{InP}(\mathrm{R}$ of $337 \mathrm{~A} / \mathrm{W}$ at $0.9 \mu \mathrm{m})$ and $\mathrm{InAs}$ ( $\mathrm{R}$ of $1.668 \times 10^{3} \mathrm{~A} / \mathrm{W}$ at $2.9 \mu \mathrm{m}$ ) nanowires, presenting a highest value of $\mathrm{R}$ when $x=0.52$ [78]. This improved performance was attributed to the fact that electron concentration $n$ of $\operatorname{InAs} x \mathrm{P}_{1-x}$ alloys was first increased and then decreased when $x$ was increased from 0 to 1 , showing the peak concentration at $x=0.52$, whereas the electron mobility remained almost unchanged because alloy scattering is not dominant at room temperature, leading to higher electron density than binary nanowires $[78,79]$.

(a)

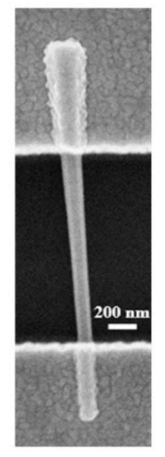

(b)

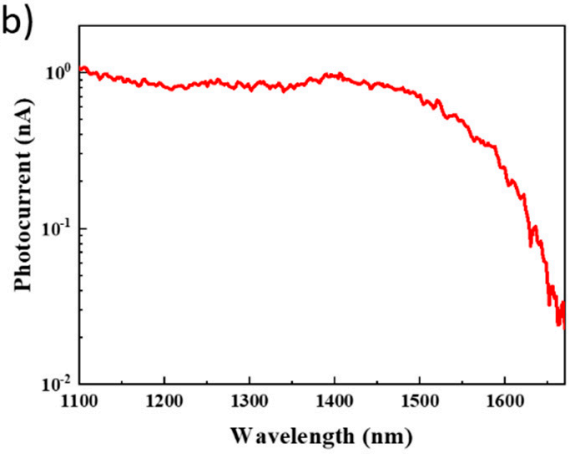

Figure 1. (a) Scanning electron microscopy (SEM) image of a single horizontal $\mathrm{GaAs}_{0.56} \mathrm{Sb}_{0.44}$ nanowire photodetector and $(\mathbf{b})$ its room temperature photocurrent spectral response at a bias of $0.15 \mathrm{~V}$. Reproduced with permission [9]. Copyright 2015, IOP Publishing Ltd. 


\subsection{Phototransistors}

Single horizontal nanowires are usually fabricated on thermally oxidized Si substrates with electrodes on the two ends of the nanowire for drain and source contacts, as shown in Figure 2a. When a gate voltage is applied to the back of the heavily doped Si substrate, a field effect transistor (FET) structure is formed [37]. Alternatively, applying an insulating layer and a contacting layer on top of the nanowire, a top-gated FET can be achieved as shown in Figure 2d [11,35]. Such transistor structures have been used for InAs photodetectors to manipulate electron trapping sites formed by the native oxide, leading to tunable positive or negative photoconductivity $[11,36,37,80,81]$. Although most semiconductors have increased conductivity under photoexcitation (positive photoconductivity (PPC)), Alexander-Webber et al. reported an unusual negative photoconductivity (NPC) of InAs nanowire-based phototransistors under visible light illumination as shown in Figure 2b [36]. This surface photo-gating effect may be explained by the fact $[36,80]$ that the free carriers in the InAs nanowire could be excited into charge trapping sites located in the surface native oxide after the absorption of light with photon energy much higher than the bandgap. It was also found that the time-dependent photoresponse of the device at increased gate voltages showed a more obvious and gradually saturated NPC behavior under illumination and increased current after the light was switched off with an optical memory effect [36]. Surface passivation of the transistors with a $90 \mathrm{~nm}$ layer of $\mathrm{Al}_{2} \mathrm{O}_{3}$ can be used to significantly reduce charge trap density with an order of magnitude increase in field-effect mobility $(\mu)$, leading to a PPC in InAs nanowires [36]. Zheng et al. demonstrated a top-gated InP nanowire photodetector in which the dark current was significantly suppressed by applying an ultrahigh electrostatic field to polarized P(VDF-TrFE) ferroelectric polymer as shown in Figure 2d-f [35]. This behavior could be maintained even when the gate voltage was removed. Very high photoconductive gain of $4.2 \times 10^{5}$, responsivity of $2.8 \times 10^{5} \mathrm{~A} / \mathrm{W}$, and specific detectivity of $9.1 \times 10^{15}$ Jones at $\lambda=0.83 \mu \mathrm{m}$ were measured [35]. More recently, Zhang et al. developed a $\mathrm{P}(\mathrm{VDF}-\mathrm{TrFE})$-coated InAs nanowire photodetector that exhibited an ultrasensitive photoresponse in a wide spectral range extending to MWIR [81,82]. The electrostatic field of the polarized ferroelectric material was capable of modifying the surface electron-hole distribution and the InAs nanowire band structure, resulting in a photoresponse at a MWIR wavelength of $4.3 \mu \mathrm{m}$ (well below the InAs band gap) and a responsivity of $9.6 \times 10^{3} \mathrm{~A} / \mathrm{W}$ and detectivity of $\sim 8.5 \times 10^{10}$ Jones $\left(\mathrm{cm} \cdot \mathrm{Hz}^{1 / 2} \mathrm{~W}^{-1}\right)$ at $77 \mathrm{~K}$ [82].

Single InAs nanowire-based FETs have also been successfully developed as highly sensitive room temperature $\mathrm{THz}$ detectors with a detection frequency range from 0.3 to $2.8 \mathrm{THz}$ [83-86]. As the active element, these FETs could work as rectifying diodes with modulated photoconductivity when the electromagnetic radiation was funneled onto a resonant or broadband antenna and excites plasma oscillations [85]. As InAs nanowires have a narrow bandgap and degenerate Fermi-level pinning, these devices are promising for bolometric detection with scaled down-dimensions when compared with planar structures [85]. In addition, these devices could be used in continuous-wave THz transmission imaging applications as demonstrated by Romeo et al. $[85,86]$. 
(a)

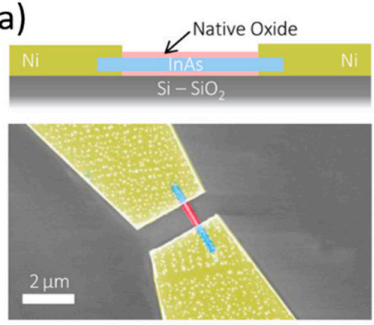

(d)

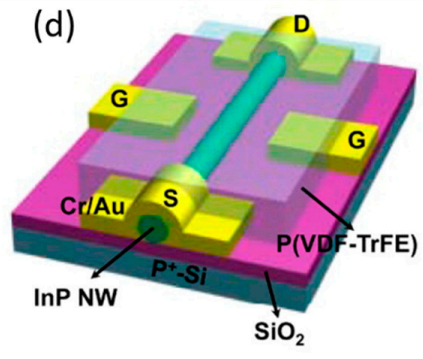

(b)

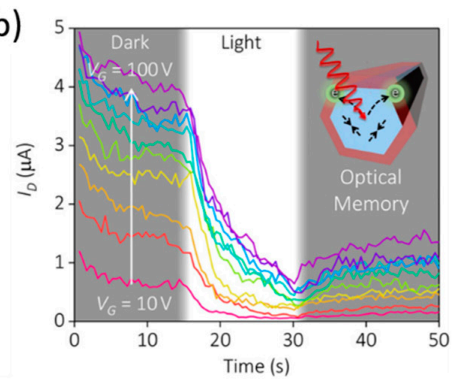

(e)

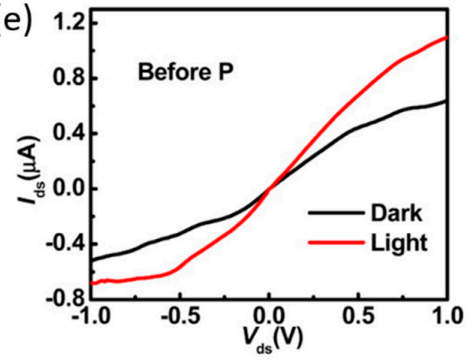

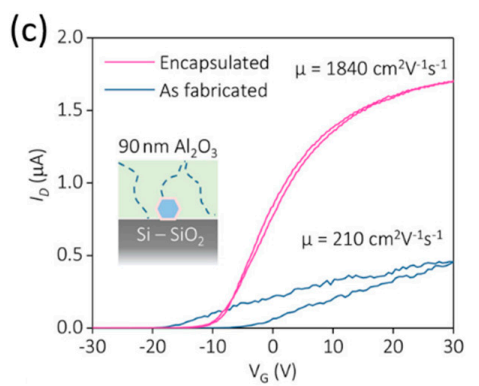

(f)

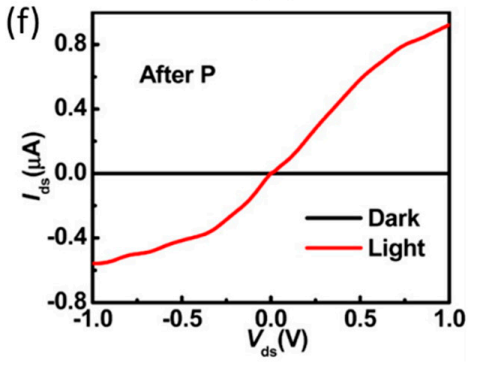

Figure 2. (a) Schematic of a back-gated single InAs nanowire phototransistor. (b) Time-dependent photoresponse of the device at various gate voltages. (c) Transfer curves of an InAs nanowire transistor before and after surface passivation of $\mathrm{Al}_{2} \mathrm{O}_{3}$, with a schematic shown in the inset indicating possible pinhole defects within the $\mathrm{Al}_{2} \mathrm{O}_{3}$ layer. Reproduced with permission [36]. Copyright 2017, American Chemical Society. (d) Schematic of a ferroelectric side-gated single InP nanowire photodetector and its $I-V$ behavior (e) before and (f) after polarization. Reproduced with permission [35]. Copyright 2016, American Chemical Society.

\subsection{Junction Based Photodetectors}

Fabrication of proper metal contacts or implementing doping can be used to form Schottky metal-semiconductor, homo- or heterojunction in nanowires for photodetection. A Schottky barrier tends to be formed when some noble metals such as $\mathrm{Au}$ and $\mathrm{Ag}$ make contact with a semiconductor such as InP and GaAs [87]. The junction at the interface between metal and semiconductor nanowire produces photocurrent with contributions from photoexcited electron-hole pairs in the semiconductor and electrons in the metal under reversed high electric field across the junction [32]. Due to the morphology and associated properties of the nanowires, the performance of these photodetectors could be tuned by adjusting the Schottky barrier height, which is sensitive to the carrier generation and transport [88]. As the photocurrent is normally localized near the metal electrode-nanowire contact, scanning photocurrent mapping can be an effective way to investigate the effects of Schottky barriers on the mechanisms of photoconduction $[32,75,89]$. Compared to the M-S structure-based Schottky barrier photodiode that can produce photocurrent at zero bias with a gain no more than 1 but very fast response time [32], the M-S-M structure is symmetrical at zero bias with a built-in potential well for photoexcited carriers until a high external voltage is applied to break through the potential barrier. Photodiodes based on the M-S-M structure have been shown to possess many desirable characteristics such as high speed, gain, and photosensitivity $[32,38,60,88]$. Thunich et al. used focused ion beam (FIB) deposition technique to form Au/GaAs Schottky junctions on a p-doped GaAs nanowire with a response time faster than $200 \mu$ s [38]. Dai et al. designed a GaAs/AlGaAs photodetector using an M-S-M radial architecture that formed built-in electric fields at the semiconductor hetero-interface and the metal/semiconductor Schottky contact to promote photogenerated charge separation and thus enhance the photosensitivity [44]. As shown in Figure 3, Fang et al. proposed a visible light-assisted dark-current suppressing method to enhance the barrier height of the metal-semiconductor contact and form an M-S-M photodiode. The dark current was reduced and the infrared photodetection was broadened from 0.83 to $3.133 \mu \mathrm{m}$ with a high responsivity of $40 \mathrm{~A} / \mathrm{W}$, detectivity of $\sim 10^{10}$ Jones, and fast response time of $80 \mu \mathrm{s}$ at $\lambda=2 \mu \mathrm{m}$ at a low bias voltage of $0.1 \mathrm{~V}$ [39]. Kuo et al. fabricated single 
InSb nanowires based on M-S-M structure (Pt-InSb-Pt) as MWIR photodetectors and demonstrated a superior responsivity of $8.4 \times 10^{4} \mathrm{~A} / \mathrm{W}$ at MWIR wavelength of $5.5 \mu \mathrm{m}$ [74].

(a)

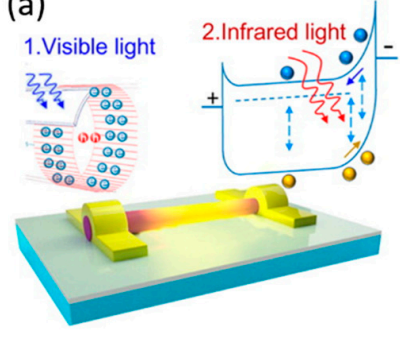

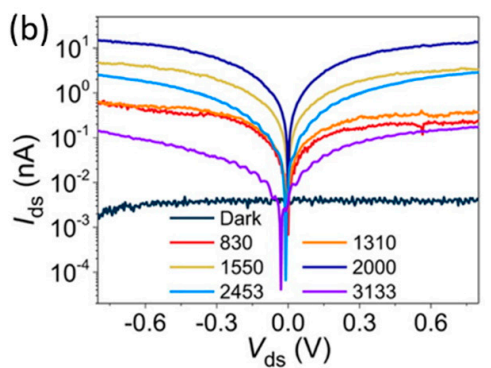

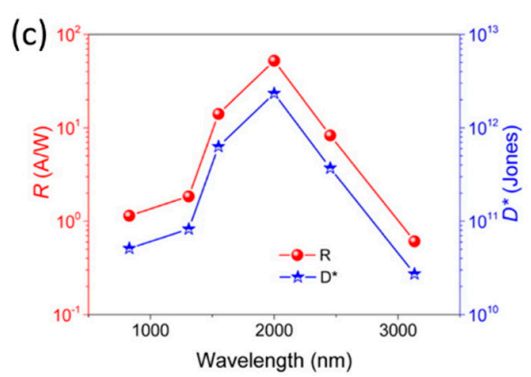

Figure 3. (a) Schematic of a single InAs infrared M-S-M photodetector and its working principle by using a visible light-assisted dark-current suppressing method. (b) Dark and light illumination $I-V$ characteristics and (c) responsivity and detectivity spectra of the fabricated detector. Reproduced with permission [39]. Copyright 2016, American Chemical Society.

In addition to the aforementioned configurations, $\mathrm{p}-\mathrm{n}$ or $\mathrm{p}$-i-n nanowire photodiodes have been employed to operate under photovoltaic mode at zero bias [33] or photoconductive mode at reverse biases. Homojunctions can be formed either axially along the nanowire or radially conforming the nanowire core by a shell [33], whereas heterojunctions are normally formed by the core-shell configuration or a nanowire vertically grown on a substrate with different materials. Such junctions showed rectifying behavior to suppress the dark current and enhance the detector's sensitivity, with relatively fast photoresponse [32]. Brenneis et al. demonstrated a Si/InAs heterojunction infrared photodetector formed by a single vertical unintentionally n-type InAs nanowire grown on a p-type $\mathrm{Si}$ substrate [43]. Miao et al. presented a graphene/InAs nanowire heterojunction photodetector with an $I_{\text {light }} / I_{\text {dark }}$ ratio of 500 at $\lambda=1 \mu \mathrm{m}$ by integrating a horizontal single InAs nanowire on a vertically stacked graphene layer as shown in Figure 4 [45]. Ma et al. reported a GaSb/GaInSb p-n heterojunction based photodetector [42]. High responsivity of $10^{3} \mathrm{~A} / \mathrm{W}, E Q E$ of $10^{4}$ and response time of $2 \mathrm{~ms}$ at the optical communication wavelength of $1.55 \mu \mathrm{m}$ were obtained by applying a high forward bias $(+1 \mathrm{~V})$. Wang et al. demonstrated a GaAsSb/InAs p-n heterojunction-based photodetector that showed a wide spectral photoresponse ranging from 0.488 to $1.8 \mu \mathrm{m}$ [90]. A responsivity of 0.0046 and $0.12 \mathrm{~A} / \mathrm{W}$ to $1.31 \mu \mathrm{m}$ telecommunication light was obtained under -0.3 and $+0.3 \mathrm{~V}$, respectively [90].
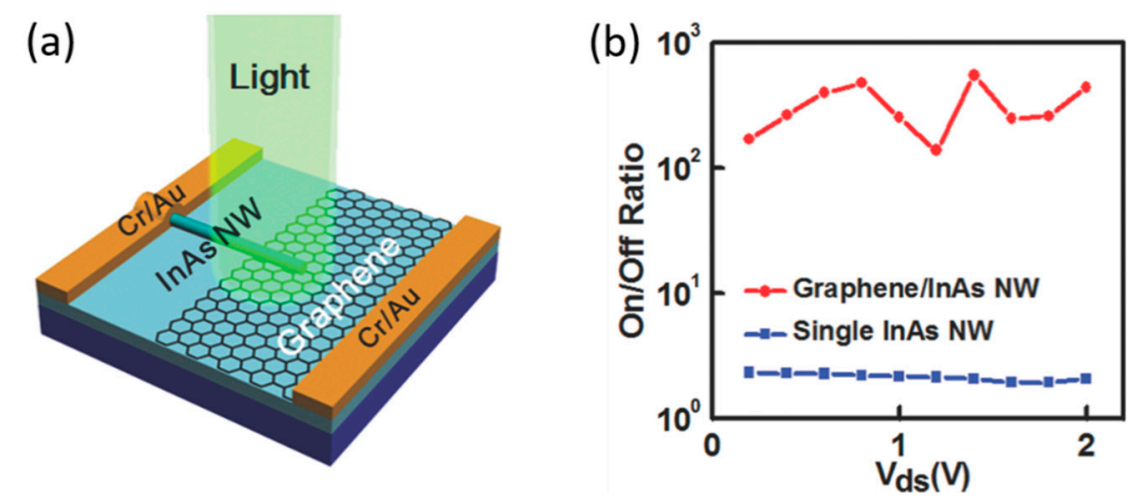

Figure 4. (a) Schematic and (b) $I_{\text {light }} / I_{\text {dark }}$ ratios of a graphene/InAs nanowire heterojunction infrared photodetector with much enhanced $I_{\text {light }} / I_{\text {dark }}$ ratio in comparison with the single horizontal InAs nanowire photodetectors. Reproduced with permission [45]. Copyright 2014, Wiley-VCH Verlag $\mathrm{GmbH} \& \mathrm{Co}$. KGaA, Weinheim.

When a photodiode operates as an avalanche photodetector (APD) at a high reverse bias condition, impact ionization leads to multiplication of holes and electrons created by the initial photon excitation, 
enabling large photocurrent gain and sensitivity. The intrinsic small photon collection area and active volume of nanowire-based APDs make them especially attractive device structures to enable photocurrent gain and sensitivity even down to the single photon level. Linear mode APDs have been reported in ensemble InGaAs/GaAs core-shell nanoneedles [91], exhibiting extremely high gain values at bias voltages significantly below breakdown [92] due to the reduction of active material volume. More significantly, a vertical InGaAs/GaAs nanowire array separate absorption-multiplication (SAM) APD operating in Geiger mode has also been demonstrated recently [93]. The nanowire array contained thousands of nanowires with each avalanche event confined in a single nanowire, drastically reducing the avalanche volume and the number of filled traps. This led to an extremely small afterpulsing probability compared with conventional InGaAs-based single-photon avalanche diodes (SPADs) and enabled operation in free-running mode up to $150 \mathrm{~K}$, which is attractive for emerging integrated photonics and quantum information applications [93].

\subsection{Photoconductive Switch $\mathrm{THz}$ Detectors}

GaAs $[94,95]$ and InP $[63,96]$ nanowires have also been explored as photoconductive terahertz $(\mathrm{THz})$ detectors, as a promising alternative to bulk semiconductor detectors due to its nanoscale spatial resolution and intrinsic polarization-resolved sensitivity. A single-nanowire photoconductive antenna (SNW-PCA) can be integrated into a pulsed THz time-domain spectroscopy (TDS) system with a Ti:sapphire laser to obtain the time-domain $\mathrm{THz}$ response ( $\mathrm{THz}$ induced photocurrent) of a nanowire detector as shown in Figure 5a,b [94]. Kun et al. successfully demonstrated a narrow bandwidth single GaAs/AlGaAs/GaAs core-shell-cap nanowire photoconductive $\mathrm{THz}$ detector that operated well in the range of 0.1 to $0.6 \mathrm{THz}$ due to local field enhancement by a simple two-pad antenna [94]. Further optimization of the antenna design yielded a single InP nanowire photoconductive detector with a high-amplitude and phase-sensitive time-domain spectrum in a broad bandwidth range of 0.1 to $2 \mathrm{THz}$ [96]. The contact quality was improved using an $\mathrm{n}^{+}-\mathrm{i}-\mathrm{n}^{+}$structure implemented for the single InP nanowire $\mathrm{THz}$ detectors, leading to enhancement of signal-to-noise ratio, 2.5 times of the undoped InP nanowire detector [63]. The function of the single nanowire $\mathrm{THz}$ detector has also been further confirmed by measuring the absorption coefficient and refractive index of paper cards in a THz-TDS system where a single InP nanowire detector was used to measure the transmitted $\mathrm{THz}$ signal through the paper card as shown in Figure 5c [96].
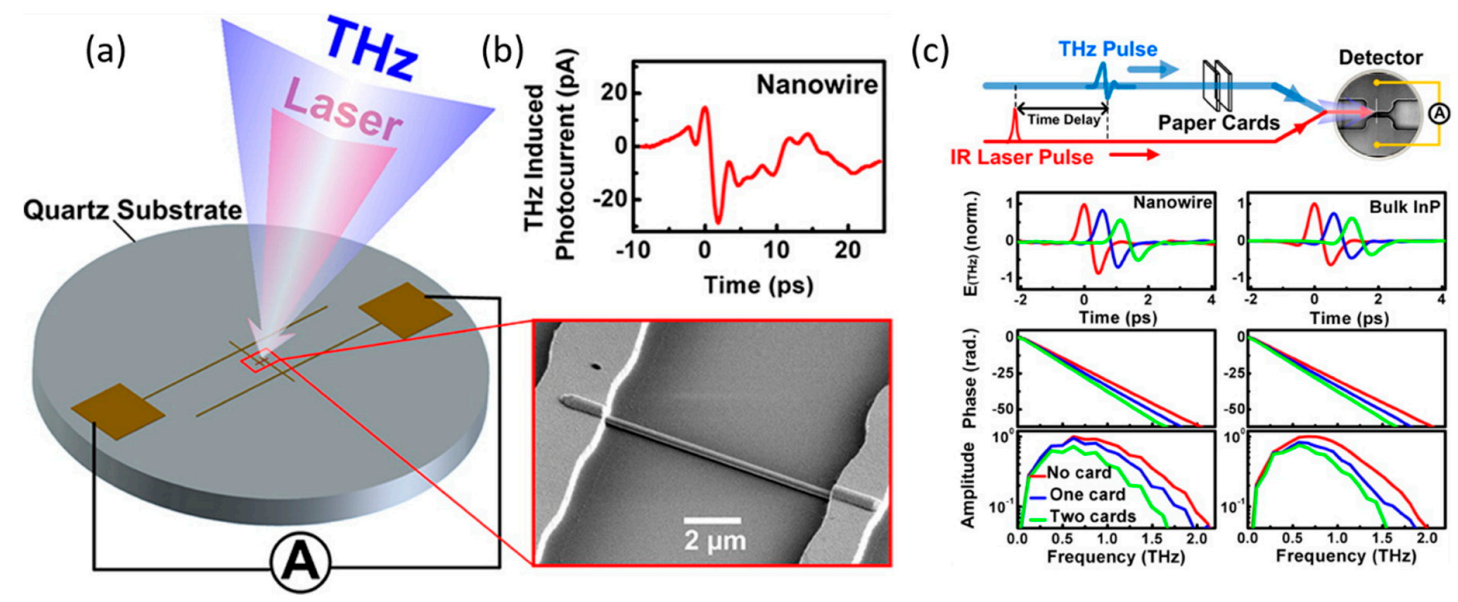

Figure 5. (a) Schematic of the detector design and optical arrangement of a single GaAs/AlGaAs/GaAs core-shell-cap nanowire photoconductive THz detector and SEM image of the central area of a fabricated device. (b) Time-domain THz response of the detector characterized in a THz-TDS system. (c) Schematic of the THz signal transmission measurement in a THz-TDS system when paper cards are presented. Reproduced with permission [94]. Copyright 2014, American Chemical Society. 


\subsection{Hybrid-Type Nanowire Detectors}

Plasmonic structures could be combined with nanowires to enhance the detector performance and polarization sensitivity. Casadei et al. demonstrated a nanowire/nanoantenna hybrid structure that could be used to engineer the polarization response of nanowires by embedding a GaAs horizontal nanowire in a bow-tie antenna array, as shown in Figure 6 [48]. The nanowire coupled with the plasmonic modes of the bow-tie nanoantennas when excited with transverse polarized light (perpendicular to the nanowire axis), thus enhancing light absorption (Figure 6a-c) and polarization photoresponse (Figure 6d-f) [48]. Senanayake et al. successfully fabricated self-aligned metal nanoholes on vertical nanopillars as a 2-dimensional (2D) plasmonic crystal to realize plasmon-enhanced photodetectors that could tune the peak responsivity wavelength and polarization with enhanced optical coupling efficiency [17,97].

(a)

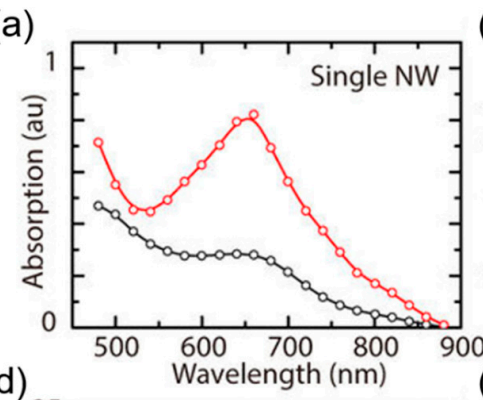

(d)

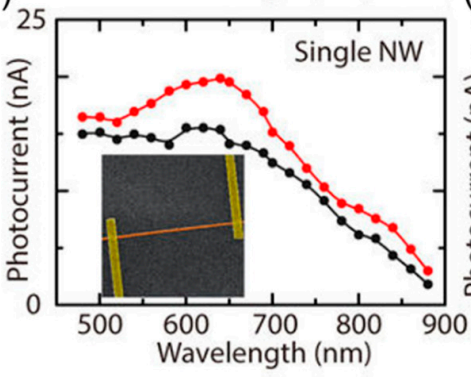

(b)

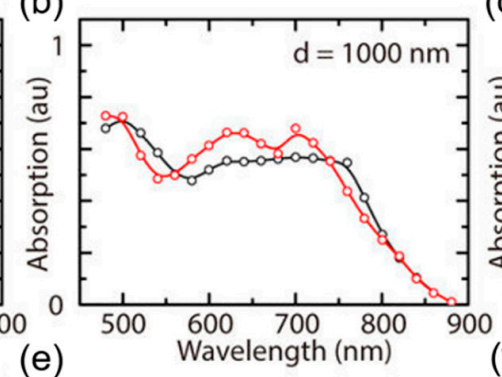

(e)

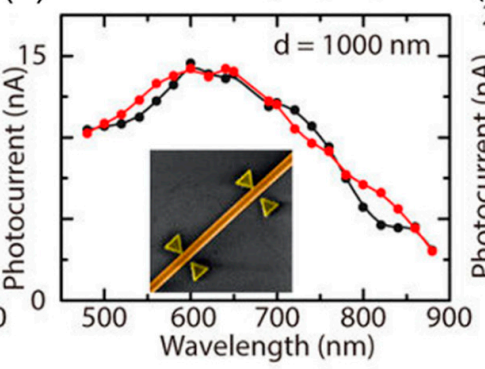

(c)

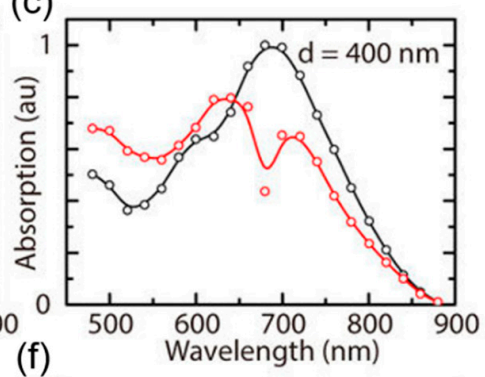

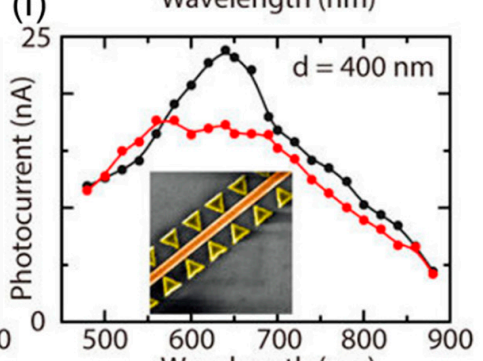

Figure 6. $(\mathbf{a}, \mathbf{b}, \mathbf{c})$ Simulated absorption spectra and $(\mathbf{d}, \mathbf{e}, \mathbf{f})$ measured photocurrent spectra of single nanowire and hybrid nanowire/nanoantenna structures for light perpendicular to the nanowire axis (black) and parallel to the nanowire axis (red), respectively. Reproduced with permission [48].

Table 1 presents a summary of the key performance metrics of the reported III-V single nanowire infrared photodetectors measured at room temperature. 
Table 1. Summary of the key performance metrics of room temperature III-V single nanowire infrared photodetectors.

\begin{tabular}{|c|c|c|c|c|c|c|c|c|c|c|}
\hline NW Material & $\begin{array}{l}\text { Band } \\
\text { Gap } \\
\text { (eV) }\end{array}$ & Growth Details & Device Structure & $\begin{array}{c}\lambda \\
(\mu \mathrm{m})\end{array}$ & $\begin{array}{c}R \\
(\mathrm{~A} / \mathrm{W})\end{array}$ & $\begin{array}{c}D^{*} \\
\text { (Jones) }\end{array}$ & $G$ & $\begin{array}{c}E Q E \\
(\%)\end{array}$ & $\begin{array}{c}t \\
(\mu \mathrm{s})\end{array}$ & Ref. \\
\hline InP & $\begin{array}{l}1.338 \text { (zincblende } \\
\text { (ZB)) and } 1.408 \\
\text { (wurtzite (WZ)) }\end{array}$ & $\begin{array}{l}\text { Bottom-up, metal } \\
\text { organic CVD } \\
\text { (MOCVD), } \\
\text { Au-assisted VLS }\end{array}$ & $\begin{array}{l}\text { Horizontal, M-S-M } \\
\text { Schottky photodiode }\end{array}$ & $0.7-1$ & & & & & & [98] \\
\hline InP & 1.34 & CVD & $\begin{array}{c}\text { Horizontal, } \\
\text { phototransistor with } \\
\text { polarization } \\
\text { ofP(VDF-TrFE) } \\
\text { ferroelectric polymer }\end{array}$ & $0.5-1.2$ & $\begin{array}{c}2.8 \times 10^{5} @ 0.83 \mu \mathrm{m}, \\
1 \mathrm{~V}\end{array}$ & $9.1 \times 10^{15}$ & $4.2 \times 10^{5}$ & & $2.91 \times 10^{4}$ & [35] \\
\hline $\operatorname{InP}$ & 1.42 & $\begin{array}{l}\text { Bottom-up, } \\
\text { MOCVD, SAE }\end{array}$ & $\begin{array}{c}\text { Horizontal, } \\
\text { photoconductor }\end{array}$ & $\begin{array}{l}0.1-2 \\
\text { THz }\end{array}$ & & & & & & [96] \\
\hline $\operatorname{InP}$ & 1.41 & $\begin{array}{l}\text { Bottom-up, } \\
\text { MOCVD, SAE }\end{array}$ & $\begin{array}{l}\text { Horizontal, } \mathrm{n}^{+}-\mathrm{i}-\mathrm{n}^{+} \\
\text {photoconductor }\end{array}$ & $0.1-2.2 \mathrm{THz}$ & & & & & & [63] \\
\hline GaAs & 1.42 & $\begin{array}{l}\text { Bottom-up, MBE, } \\
\text { Ga-assisted VLS }\end{array}$ & $\begin{array}{l}\text { Horizontal, Schottky } \\
\text { photodiode }\end{array}$ & $0.7-1$ & & & & & 167 & [38] \\
\hline GaAs & 1.42 & $\begin{array}{c}\text { Bottom-up, } \\
\text { MOCVD, } \\
\text { Au-assisted VLS }\end{array}$ & $\begin{array}{l}\text { Horizontal, M-S-M } \\
\text { Schottky photodiode }\end{array}$ & $0.4-1.2$ & & & $2 \times 10^{4}$ & & & [88] \\
\hline GaAs & $\begin{array}{c}1.51 \text { for undoped } \\
\text { NW@77 K; } \\
1.45 \text { for 2 } \\
\times 10^{17} \mathrm{~cm}^{-3} \\
\text { n-doped NW@77 K }\end{array}$ & Bottom-up, MBE & $\begin{array}{l}\text { Vertical on GaAs } \\
\text { substrate, Schottky } \\
\text { photodiode }\end{array}$ & 0.808 & $\begin{array}{c}5.3 \times 10^{-7} @ 10 \mathrm{~V} \text { for } \\
\text { undoped NW; } 1.5 \times \\
10^{-7} @ 10 \mathrm{~V} \text { for } 2 \times \\
10^{17} \mathrm{~cm}^{-3} \mathrm{n} \text {-doped } \\
\mathrm{NW}\end{array}$ & & & & $1 \times 10^{-6}$ & [66] \\
\hline $\begin{array}{l}\text { i-GaAs } / \mathrm{p}-\mathrm{GaAs} \\
\text { core-shell }\end{array}$ & & Bottom-up & $\begin{array}{c}\text { Horizontal, } \\
\text { photoconductor with } \\
\text { electrical contact on } \\
\text { p-type shell }\end{array}$ & $0.48-0.88$ & & & & & & [48] \\
\hline $\begin{array}{c}\text { GaAs/ } \\
\text { AlGaAs } \\
\text { core-shell }\end{array}$ & & $\begin{array}{c}\text { Bottom-up, } \\
\text { MOCVD, } \\
\text { Au-assisted VLS }\end{array}$ & $\begin{array}{l}\text { Horizontal, } \\
\text { M-S-M Schottky } \\
\text { photodiode }\end{array}$ & 0.8 & $10^{-4}$ & & & 13.5 & $5 \times 10^{-3}$ & [71] \\
\hline $\begin{array}{c}\text { GaAs/ } \\
\text { AlGaAs } \\
\text { core-shell }\end{array}$ & & $\begin{array}{c}\text { Bottom-up, } \\
\text { MOCVD, } \\
\text { Au-assisted VLS }\end{array}$ & $\begin{array}{l}\text { Horizontal, M-S-M } \\
\text { Schottky photodiode }\end{array}$ & $0.5-0.9$ & & & & & & [89] \\
\hline
\end{tabular}


Table 1. Cont

\begin{tabular}{|c|c|c|c|c|c|c|c|c|c|c|}
\hline NW Material & $\begin{array}{l}\text { Band } \\
\text { Gap } \\
(\mathrm{eV})\end{array}$ & Growth Details & Device Structure & $\begin{array}{c}\lambda \\
(\mu \mathrm{m})\end{array}$ & $\begin{array}{c}R \\
(\mathrm{~A} / \mathrm{W})\end{array}$ & $\begin{array}{c}D^{*} \\
\text { (Jones) }\end{array}$ & $G$ & $\begin{array}{l}E Q E \\
(\%)\end{array}$ & $\begin{array}{c}t \\
(\mu \mathrm{s})\end{array}$ & Ref. \\
\hline $\begin{array}{c}\text { GaAs/ } \\
\text { hight-T GaAs/ } \\
\text { AlGaAs } \\
\text { core-multi } \\
\text { shell }\end{array}$ & 1.412 & $\begin{array}{c}\text { Bottom-up, } \\
\text { MOCVD, } \\
\text { Au-assisted VLS }\end{array}$ & $\begin{array}{l}\text { Horizontal, radial } \\
\text { heterojunction } \\
\text { M-S-M Schottky } \\
\text { photodiode }\end{array}$ & $0.3-0.9$ & $0.57 @ 0.855 \mu \mathrm{m}, 1 \mathrm{~V}$ & $7.20 \times 10^{10}$ & & & & [44] \\
\hline $\begin{array}{c}\text { GaAs/ } \\
\text { AlGaAs/GaAs } \\
\text { core-shell-cap }\end{array}$ & 1.43 & $\begin{array}{c}\text { Bottom-up, } \\
\text { MOCVD, } \\
\text { Au-assisted VLS }\end{array}$ & $\begin{array}{l}\text { Horizontal, } \\
\text { photoconductor }\end{array}$ & $0.1-0.6 \mathrm{THz}$ & & & & & $4.6 \times 10^{-3}$ & [94] \\
\hline $\begin{array}{c}\text { GaAs/ } \\
\text { AlGaAs/GaAs } \\
\text { core-shell-cap }\end{array}$ & 1.43 & $\begin{array}{c}\text { Bottom-up, } \\
\text { MOCVD, } \\
\text { Au-assisted VLS }\end{array}$ & $\begin{array}{c}\text { Horizontal, } \\
\text { photoconductor }\end{array}$ & $0.1-1.5 \mathrm{THz}$ & & & & & $4.6 \times 10^{-3}$ & [95] \\
\hline $\mathrm{GaSb}$ & 0.725 & $\begin{array}{l}\text { Horizontal tube } \\
\text { furnace, CVD }\end{array}$ & $\begin{array}{c}\text { Horizontal, } \\
\text { photoconductor }\end{array}$ & $0.35-0.8$ & $443.3 @ 0.8 \mu \mathrm{m}, 0.4 \mathrm{~V}$ & $\begin{array}{c}2.86 \times 10^{9} @ \\
0.8 \mu \mathrm{m}\end{array}$ & & $\begin{array}{c}688.4 @ 0.8 \\
\mu \mathrm{m}\end{array}$ & $\begin{array}{c}2 \times 10^{5} @ 0.6 \\
\mu \mathrm{m}\end{array}$ & [73] \\
\hline $\begin{array}{c}\mathrm{GaSb} / \\
\mathrm{GaInSb}\end{array}$ & $\begin{array}{c}0.75 \text { for } \mathrm{GaSb} @ 77 \mathrm{~K} \text {; } \\
0.625 \text { for } \mathrm{Ga}_{0.9} \\
\mathrm{In}_{0.1} \\
\mathrm{Sb} @ 77 \mathrm{~K} \\
\end{array}$ & $\begin{array}{l}\text { Horizontal tube } \\
\text { furnace, CVD }\end{array}$ & $\begin{array}{l}\text { Horizontal, } \\
\text { p-n heterojunction } \\
\text { photodiode }\end{array}$ & $0.78-2.25$ & $\begin{array}{c}1.5 \times 10^{3} @ 1.55 \mu \mathrm{m}, \\
1 \mathrm{~V}\end{array}$ & & & $8.5 \times 10^{6}$ & $2 \times 10^{3}$ & [42] \\
\hline InAs & 0.354 & $\begin{array}{l}\text { Bottom-up, CVD, } \\
\text { Au-assisted }\end{array}$ & $\begin{array}{c}\text { Horizontal, } \\
\text { photoconductor \& } \\
\text { phototransistor }\end{array}$ & $0.3-1.1$ & $\begin{array}{c}4.4 \times 10^{3} @ \\
0.532 \mu \mathrm{m}, 15 \mathrm{~V}\end{array}$ & $2.6 \times 10^{11}$ & & $1.03 \times 10^{6}$ & & [99] \\
\hline InAs & 0.365 & $\begin{array}{l}\text { Bottom-up, MBE, } \\
\text { Au-assisted }\end{array}$ & $\begin{array}{c}\text { Horizontal, } \\
\text { photoconductor Schottky } \\
\text { photodiode \& } \\
\text { phototransistor }\end{array}$ & $0.632-1.47$ & $\begin{array}{c}5.3 \times 10^{3} \text { for } \\
\text { photodiode; } \\
1.9 \times 10^{3} \text { for } \\
\text { photoconductor }\end{array}$ & & & & & [11] \\
\hline InAs & 0.35 & $\begin{array}{l}\text { Bottom-up, MBE, } \\
\text { Au-assisted }\end{array}$ & $\begin{array}{l}\text { Horizontal, } \\
\text { photoconductor \& } \\
\text { phototransistor }\end{array}$ & $0.5-1.6$ & $-3 \times 10^{4} @ 0.2 \mathrm{~V}$ & & $-7.5 \times 10^{4}$ & & $<100$ & [80] \\
\hline InAs & 0.35 & $\begin{array}{l}\text { Bottom-up, MBE, } \\
\text { Au-assisted VLS }\end{array}$ & $\begin{array}{l}\text { Horizontal, M-S-M } \\
\text { Schottky photodiode, VIS } \\
\text { light }(450 \mathrm{~nm}) \text {-assisted }\end{array}$ & $0.83-3.133$ & $\begin{array}{c}40 @ 2 \mu \mathrm{m}, 0.1 \mathrm{~V} ; \\
0.6 @ 3.113 \mu \mathrm{m}, 0.4 \mathrm{~V}\end{array}$ & $\begin{array}{c}2 \times 10^{12} @ 2 \\
\mu \mathrm{m} ; \\
10^{10} @ 3.113 \\
\mu \mathrm{m}\end{array}$ & & & 80 & [39] \\
\hline InAs & & $\begin{array}{l}\text { Bottom-up, } \\
\text { MOCVD, } \\
\text { self-assisted }\end{array}$ & $\begin{array}{c}\text { Horizontal, } \\
\text { phototransistor }\end{array}$ & $0.633,0.65-1$ & & & & & $<2.5 \times 10^{5}$ & [37] \\
\hline
\end{tabular}


Table 1. Cont

\begin{tabular}{|c|c|c|c|c|c|c|c|c|c|c|}
\hline NW Material & $\begin{array}{l}\text { Band } \\
\text { Gap } \\
(\mathrm{eV})\end{array}$ & Growth Details & Device Structure & $\begin{array}{c}\lambda \\
(\mu \mathrm{m})\end{array}$ & $\begin{array}{c}R \\
(\mathrm{~A} / \mathrm{W})\end{array}$ & $\begin{array}{c}D^{*} \\
\text { (Jones) }\end{array}$ & $G$ & $\begin{array}{l}E Q E \\
(\%)\end{array}$ & $\begin{array}{c}t \\
(\mu \mathrm{s})\end{array}$ & Ref. \\
\hline InAs & 0.477 & $\begin{array}{c}\text { Bottom-up, } \\
\text { MOCVD, } \\
\text { Au-assisted VLS }\end{array}$ & $\begin{array}{c}\text { Horizontal, } \\
\text { phototransistor }\end{array}$ & $\begin{array}{l}\text { halogen lamp } \\
\text { with a peak@ } \\
0.906 \mu \mathrm{m} \\
(1.37 \mathrm{eV}) \\
\end{array}$ & & & & & & [36] \\
\hline InAs & & $\begin{array}{c}\text { Bottom-up, } \\
\text { chemical beam } \\
\text { epitaxy (CBE), } \\
\text { Au-assisted VLS }\end{array}$ & $\begin{array}{c}\text { Horizontal, } \\
\text { phototransistor }\end{array}$ & $0.3 \mathrm{THz}$ & $\begin{array}{c}>1 \mathrm{~V} / \mathrm{W}_{\mathrm{gS}}=-7 \mathrm{~V} \\
\text { and } \mathrm{V}_{\mathrm{ds}}=0.01 \mathrm{~V}\end{array}$ & & & & & [83] \\
\hline InAs & & $\begin{array}{l}\text { Bottom-up, CBE, } \\
\text { Au-assisted VLS }\end{array}$ & $\begin{array}{c}\text { Horizontal, } \\
\text { phototransistor }\end{array}$ & $1.5 \mathrm{THz}$ & $\begin{array}{c}12 \mathrm{~V} / \mathrm{W} @ \mathrm{~V}_{\mathrm{gs}}=-2 \mathrm{~V} \\
\text { and } \mathrm{V}_{\mathrm{ds}}=0.005 \mathrm{~V}\end{array}$ & & & & & [84] \\
\hline InAs & & $\begin{array}{l}\text { Bottom-up, CBE, } \\
\text { Au-assisted VLS }\end{array}$ & $\begin{array}{c}\text { Horizontal, } \\
\text { phototransistor }\end{array}$ & $0.3 \mathrm{THz}$ & $100 \mathrm{~V} / \mathrm{W} @ \mathrm{~V}_{\mathrm{gs}}=5 \mathrm{~V}$ & & & & & [85] \\
\hline InAs & & $\begin{array}{l}\text { Bottom-up, CBE, } \\
\text { Au-assisted VLS }\end{array}$ & $\begin{array}{c}\text { Horizontal, } \\
\text { phototransistor }\end{array}$ & $2.8 \mathrm{THz}$ & $\begin{array}{l}5 \mathrm{~V} / \mathrm{W} @ \mathrm{~V}_{\mathrm{gs}}=8 \mathrm{~V} \\
\text { and } \mathrm{V}_{\mathrm{ds}}=0.025 \mathrm{~V}\end{array}$ & & & & & [86] \\
\hline InAs/Si & 0.36 & $\begin{array}{l}\text { Bottom-up, MBE, } \\
\text { SAE }\end{array}$ & $\begin{array}{c}\text { Vertical InAs NW on } \\
\text { p-type Si substrate, } \\
\text { p-n heterojunction } \\
\text { photodiode }\end{array}$ & 1.47 & & & & & & [43] \\
\hline $\begin{array}{c}\text { InAs/ } \\
\text { Graphene }\end{array}$ & & $\begin{array}{l}\text { Bottom-up, MBE, } \\
\text { Au-assisted }\end{array}$ & $\begin{array}{l}\text { Horizontal, hetero } \\
\text { junction photodetector }\end{array}$ & $0.457-1$ & 0.5 & & & & & [45] \\
\hline $\mathrm{InSb}$ & 0.18 & $\begin{array}{l}\text { Bottom-up, direct } \\
\text { current (DC) electro } \\
\text { deposition } \\
\text { with AAO template }\end{array}$ & $\begin{array}{l}\text { Horizontal, } \\
\text { photoconductor \& M-S-M } \\
\text { Schottky photodiode }\end{array}$ & $0.5-1$ & & & & & & [100] \\
\hline $\mathrm{InSb}$ & $0.17-0.4$ & $\begin{array}{l}\text { Bottom-up, tube } \\
\text { furnace, Au-assisted } \\
\text { VLS }\end{array}$ & $\begin{array}{l}\text { Horizontal, Schottky } \\
\text { photodiode }\end{array}$ & $\begin{array}{l}1000^{\circ} \mathrm{C} \text { black } \\
\text { body radiation }\end{array}$ & & & & 60 & & [41] \\
\hline $\mathrm{InSb}$ & 0.17 & $\begin{array}{l}\text { Bottom-up, } \\
\text { electrochemical } \\
\text { method with AAO } \\
\text { template }\end{array}$ & $\begin{array}{l}\text { Horizontal, } \\
\text { M-S-M Schottky } \\
\text { photodiode }\end{array}$ & 5.5 & $8.4 \times 10^{4}$ & & & $1.96 \times 10^{6}$ & $2.6 \times 10^{5}$ & [74] \\
\hline
\end{tabular}


Table 1. Cont.

\begin{tabular}{|c|c|c|c|c|c|c|c|c|c|c|}
\hline NW Material & $\begin{array}{l}\text { Band } \\
\text { Gap } \\
(\mathrm{eV})\end{array}$ & Growth Details & Device Structure & $\begin{array}{c}\lambda \\
(\mu \mathrm{m})\end{array}$ & $\begin{array}{c}R \\
(\mathrm{~A} / \mathrm{W})\end{array}$ & $\begin{array}{c}D^{*} \\
\text { (Jones) }\end{array}$ & G & $\begin{array}{l}E Q E \\
(\%)\end{array}$ & $\begin{array}{c}t \\
(\mu \mathrm{s})\end{array}$ & Ref. \\
\hline InAsP & $\begin{array}{c}1.416(\mathrm{InP})-0.421 \\
\text { (InAs) }\end{array}$ & $\begin{array}{c}\text { VLS and } \\
\text { ion-exchange (IE) }\end{array}$ & $\begin{array}{c}\text { Horizontal, } \\
\text { photoconductor }\end{array}$ & $0.7-3.5$ & $\begin{array}{c}1668 @ 2.9 \mu \mathrm{m}, 0.5 \mathrm{~V} \\
\text { for InAs; } 4998 @ 2.3 \\
\mu \mathrm{m} \text { for InAs } \mathrm{s}_{0.8} \mathrm{P}_{0.2} ; \\
5417 @ 1.7 \mu \mathrm{m}, 0.5 \mathrm{~V} \\
\text { for InAs } \mathrm{s}_{0.52} \mathrm{P}_{0.48 ;} \\
3833 @ 1.2 \mu \mathrm{m}, 0.5 \mathrm{~V} \\
\text { for InAs } \mathrm{s}_{0.25} \mathrm{P}_{0.75 ;} \\
337 @ 0.9 \mu \mathrm{m}, 0.5 \mathrm{~V} \\
\text { for InP }\end{array}$ & & & $\begin{array}{c}7.15 \times 10^{4} \\
\text { for InAs; } \\
2.7 \times 10^{5} \\
\text { for } \operatorname{InAs}_{0.8} \\
\mathrm{P}_{0.2 ;} ; \\
3.96 \times 10^{5} \\
\text { for } \\
\text { InAs }_{0.52} \\
\mathrm{P}_{0.48 ;} ; \\
3.67 \times 10^{5} \\
\text { for } \\
\text { InAs } \\
\mathrm{P}_{0.25} \\
4.65 \times 10^{4} \\
\text { for InP }\end{array}$ & & [78] \\
\hline InGaAs & $\begin{array}{l}0.69 @ 77 \mathrm{~K} \text { for } \\
\operatorname{In}_{0.65} \mathrm{Ga}_{0.35} \mathrm{As}\end{array}$ & $\begin{array}{c}\text { Bottom-up, CVD, } \\
\text { Au-assisted }\end{array}$ & $\begin{array}{c}\text { Horizontal, } \\
\text { photoconductor }\end{array}$ & $1.1-2$ & $\begin{array}{c}6.5 \times 10^{3} @ 1.6 \mu \mathrm{m} \\
0.5 \mathrm{~V}\end{array}$ & & & $5.04 \times 10^{5}$ & $7 \times 10^{4}$ & [77] \\
\hline GaAsSb & $\begin{array}{c}0.9 @ 77 \mathrm{~K} \text { for } \mathrm{Ga} \\
\mathrm{As}_{0.26} \mathrm{Sb}_{0.74}\end{array}$ & CVD & $\begin{array}{c}\text { Horizontal, } \\
\text { photoconductor }\end{array}$ & $1.16-1.55$ & $\begin{array}{c}1.7 \times 10^{3} @ 1.31 \mu \mathrm{m} \\
1 \mathrm{~V} \\
\end{array}$ & & & $1.62 \times 10^{5}$ & $6 \times 10^{4}$ & [101] \\
\hline GaAsSb & $\begin{array}{l}0.827 \text { for } \mathrm{Ga} \\
\mathrm{As}_{0.56} \mathrm{Sb}_{0.44}\end{array}$ & $\begin{array}{c}\text { Bottom-up, } \\
\text { MOCVD, } \\
\text { Au-assisted VLS }\end{array}$ & $\begin{array}{c}\text { Horizontal, } \\
\text { photoconductor }\end{array}$ & $1.1-1.66$ & $\begin{array}{c}2.37 @ 1.3 \mu \mathrm{m}, 0.15 \mathrm{~V} \\
1.44 @ 1.55 \mu \mathrm{m}, 0.15 \\
\mathrm{~V}\end{array}$ & $\begin{array}{c}1.08 \times 10^{9} @ \\
1.3 \mu \mathrm{m} ; 6.55 \\
\times 10^{8} @ 1.55 \\
\mu \mathrm{m}\end{array}$ & & & & [9] \\
\hline GaAsSb/InAs & $\begin{array}{c}1.1 \text { for } \mathrm{Ga} \\
\mathrm{As}_{0.82} \mathrm{Sb}_{0.18}\end{array}$ & $\begin{array}{c}\text { Bottom-up, } \\
\text { solid-source MBE, } \\
\text { self-assisted VLS }\end{array}$ & $\begin{array}{l}\text { Horizontal, p-n } \\
\text { heterojunction } \\
\text { photodiode }\end{array}$ & $0.488-1.8$ & $0.12 @ 1.31 \mu \mathrm{m}, 0.3 \mathrm{~V}$ & & & 12 & $\begin{array}{c}4.5 \times \\
10^{2} @ 0.633 \\
\mu \mathrm{m}\end{array}$ & [90] \\
\hline $\mathrm{GaAsSb} / \mathrm{InP}$ & 0.92 for $\mathrm{As}_{0.66} \mathrm{Sb}_{0.34}$ & $\begin{array}{c}\text { Bottom-up, } \\
\text { MOCVD, } \\
\text { Au-assisted VLS }\end{array}$ & $\begin{array}{l}\text { Horizontal, } \\
\text { photoconductor }\end{array}$ & $1.05-1.55$ & $\begin{array}{l}\text { 143.5@1.3 } \mu \mathrm{m}, 1.5 \mathrm{~V} \\
\text { for GaAsSb } \\
\text { core-only; } \\
325.1 @ 1.3 \mu \mathrm{m}, 1.5 \mathrm{~V} \\
\text { for GaAsSb/InP } \\
\text { core-shell }\end{array}$ & $\begin{array}{c}5.3 \times \\
10^{10} @ 1.3 \mu \mathrm{m}, \\
1.5 \mathrm{~V} \text { for } \\
\text { GaAsSb } \\
\text { core-only; } \\
4.7 \times \\
10^{10} @ 1.3 \mu \mathrm{m}, \\
1.5 \mathrm{~V} \text { for } \\
\text { GaAsSb/InP } \\
\text { core-shell }\end{array}$ & & $\begin{array}{l}1.37 \times 10^{4} \\
\quad \text { for } \\
\text { GaAsSb } \\
\text { core-only; } \\
3.1 \times 10^{4} \\
\quad \text { for } \\
\text { GaAsSb/InP } \\
\text { core-shell; }\end{array}$ & & [76] \\
\hline
\end{tabular}




\section{Challenges and Future Perspectives}

Although III-V semiconductor nanowires present unique and excellent optical and electrical properties and have been demonstrated to have promising performance for room temperature infrared photodetection, there are still many technological challenges to overcome. Despite good device performance, the output current of the single nanowire photodetectors is still too low for practical applications. Therefore, the fabrication technique for large-scale and controlled assembly of single nanowires into horizontal arrays is highly desirable [102]. There have been a few techniques reported for nanowire position alignment, such as optical tweezers [103], electric field-assisted assembly technique [102,104], elastomeric poly(dimethylsiloxane) (PDMS) stamp-assisted transfer [105], Langmuir-Blodgett method [106], bespoke polymer $\mu$-stamp-assisted nano-scale transfer printing technique $[107,108]$, as well as a large-scale transfer printing technique known as contact printing $[53,109]$, by simply transferring nanowires from the growth substrate to a patterned receiver substrate. However, there is always a trade-off between the accuracy of nanowire positioning and scalability of the technique. This requires further development of the technology for high-performance, stable-operation, and low-cost assembly of horizontal nanowire arrays on both rigid and flexible substrates.

Another limitation of III-V semiconductor nanowire photodetectors is their detection wavelength that are determined by the material bandgap, especially for the relatively easy synthesis but wider bandgap binary materials such as GaAs and InP. To enable light detection of photon energies well below the semiconductor bandgap, Knight et al. proposed a novel idea of active optical antennas, in which hot carriers are generated and injected into the semiconductor material (e.g., Si substrate) through the antenna-semiconductor Schottky barrier, contributing to a detectable photocurrent response at SWIR wavelengths up to $1.6 \mu \mathrm{m}$ [110]. To further extend the nanowire photodetector photoresponse range to long-wavelength infrared (LWIR), 0-dimensional (0D) nanomaterials, such as semiconductor quantum dots (QDs) and quantum wells (QWs), could be incorporated into nanowire structures. Synthesis of single or multiple low-bandgap InAsP quantum discs (QDiscs) within an InP nanowire axially was demonstrated by Karimi et al. such that the intersubband transitions in the conduction band of the InAsP QDiscs enabled broad infrared response ranging from 3 to $20 \mu \mathrm{m}$ [111].

\section{Conclusions}

Single III-V semiconductor nanowires have been extensively explored in the past decade as room temperature high-performance infrared photodetectors with broad detection wavelength range covering UV, VIS, IR, and THz regimes. In this article, we present a review on their recent development in materials, structures, and comparative performances, as well as the existing challenges and possible future directions.

Author Contributions: Writing-original draft preparation, Z.L. and L.F.; writing-review, revision and editing, J.A., M.A., H.H.T., and C.J. All authors have read and agreed to the published version of the manuscript.

Funding: This research was funded by The Australian Research Council (ARC) and Air Force of Scientific Research (AFOSR).

Acknowledgments: J.A. and M.A. are thankful for the support by Air Force Research Laboratory Munitions Directorate (D. Lambert) and Air Force Research Laboratory AFOSR Directorate/AOARD matching funds (J. Chen).

Conflicts of Interest: The authors declare no conflicts of interest.

\section{References}

1. LaPierre, R.R.; Robson, M.; Azizur-Rahman, K.M.; Kuyanov, P. A review of III-V nanowire infrared photodetectors and sensors. J. Phys. D Appl. Phys. 2017, 50, 123001. [CrossRef]

2. Teng, F.; Hu, K.; Ouyang, W.; Fang, X. Photoelectric Detectors Based on Inorganic p-Type Semiconductor Materials. Adv. Mater. 2018, 30, 1706262. [CrossRef] [PubMed] 
3. InAs Photovoltaic Detectors. Available online: https://www.hamamatsu.com/jp/en/product/optical-sensors/ infrared-detector/inas-photovoltaic-detector/index.html (accessed on 10 February 2020).

4. InSb Photoconductive Detectors. Available online: https://www.hamamatsu.com/jp/en/product/opticalsensors/infrared-detector/insb-photoconductive-detector/index.html (accessed on 10 February 2020).

5. InSb Photovoltaic Detectors. Available online: https:/www.hamamatsu.com/jp/en/product/optical-sensors/ infrared-detector/insb-photovoltaic-detector/index.html (accessed on 10 February 2020).

6. InAsSb Photovoltaic Detectors. Available online: https://www.hamamatsu.com/jp/en/product/opticalsensors/infrared-detector/inassb-photovoltaic-detector/index.html (accessed on 10 February 2020).

7. Tennant, W.E.; Gulbransen, D.J.; Roll, A.; Carmody, M.; Edwall, D.; Julius, A.; Dreiske, P.; Chen, A.; McLevige, W.; Freeman, S.; et al. Small-pitch HgCdTe photodetectors. J. Electron. Mater. 2014, 43, 3041-3046. [CrossRef]

8. Ren, D.; Rong, Z.; Azizur-Rahman, K.M.; Somasundaram, S.; Shahili, M.; Huffaker, D.L. Feasibility of achieving high detectivity at short-and mid-wavelength infrared using nanowire-plasmonic photodetectors with $p-n$ heterojunctions. Nanotechnology 2019, 30, 044002. [CrossRef]

9. Li, Z.; Yuan, X.; Fu, L.; Peng, K.; Wang, F.; Fu, X.; Caroff, P.; White, T.P.; Tan, H.H.; Jagadish, C. Room temperature GaAsSb single nanowire infrared photodetectors. Nanotechnology 2015, 26, 445202. [CrossRef]

10. Weng, W.Y.; Hsueh, T.J.; Chang, S.J.; Wang, S.B.; Hsueh, H.T.; Huang, G.J. A high-responsivity GaN nanowire UV photodetector. IEEE J. Sel. Top. Quantum Electron. 2011, 17, 996-1001. [CrossRef]

11. Miao, J.; Hu, W.; Guo, N.; Lu, Z.; Zou, X.; Liao, L.; Shi, S.; Chen, P.; Fan, Z.; Ho, J.C.; et al. Single InAs nanowire room-temperature near-infrared photodetectors. ACS Nano 2014, 8, 3628-3635. [CrossRef]

12. An, Q.; Meng, X.; Xiong, K.; Qiu, Y. A high-performance fully nanostructured individual CdSe nanotube photodetector with enhanced responsivity and photoconductive gain. J. Mater. Chem. C 2017, 5, 7057-7066. [CrossRef]

13. Liu, Y.; Wei, N.; Zeng, Q.; Han, J.; Huang, H.; Zhong, D.; Wang, F.; Ding, L.; Xia, J.; Xu, H.; et al. Room Temperature Broadband Infrared Carbon Nanotube Photodetector with High Detectivity and Stability. Adv. Opt. Mater. 2016, 4, 238-245. [CrossRef]

14. Zhang, D.-Y.; Ge, C.-W.; Wang, J.-Z.; Zhang, T.-F.; Wu, Y.-C.; Liang, F.-X. Single-layer graphene-TiO 2 nanotubes array heterojunction for ultraviolet photodetector application. Appl. Surf. Sci. 2016, 387, 1162-1168. [CrossRef]

15. Ajiki, Y.; Kan, T.; Yahiro, M.; Hamada, A.; Adachi, J.; Adachi, C.; Matsumoto, K.; Shimoyama, I. Silicon based near infrared photodetector using self-assembled organic crystalline nano-pillars. Appl. Phys. Lett. 2016, 108, 151102. [CrossRef]

16. Chun, D.H.; Choi, Y.J.; In, Y.; Nam, J.K.; Choi, Y.J.; Yun, S.; Kim, W.; Choi, D.; Kim, D.; Shin, H.; et al. Halide Perovskite Nanopillar Photodetector. ACS Nano 2018, 12, 8564-8571. [CrossRef] [PubMed]

17. Lee, W.-J.; Senanayake, P.; Farrell, A.C.; Lin, A.; Hung, C.-H.; Huffaker, D.L. High Quantum Efficiency Nanopillar Photodiodes Overcoming the Diffraction Limit of Light. Nano Lett. 2016, 16, 199-204. [CrossRef] [PubMed]

18. Lin, T.-S.; Chen, C.-H.; Lee, C.-T. Physical Internal Gain Mechanisms of ZnO-Based Nanorod Ultraviolet Photodetectors. IEEE Photonics Technol. Lett. 2015, 27, 759-762.

19. Ji, T.; Liu, Q.; Zou, R.; Sun, Y.; Xu, K.; Sang, L.; Liao, M.; Koide, Y.; Yu, L.; Hu, J. An Interface Engineered Multicolor Photodetector Based on n-Si (111)/ $\mathrm{TiO}_{2}$ Nanorod Array Heterojunction. Adv. Funct. Mater. 2016, 26, 1400-1410. [CrossRef]

20. Young, S.-J.; Liu, Y.-H. Low-frequency noise properties of $\mathrm{MgZnO}$ nanorod ultraviolet photodetectors with and without UV illumination. Sensors Actuators Phys. 2018, 269, 363-368. [CrossRef]

21. Guo, Q.; Pospischil, A.; Bhuiyan, M.; Jiang, H.; Tian, H.; Farmer, D.; Deng, B.; Li, C.; Han, S.-J.; Wang, H.; et al. Black Phosphorus Mid-Infrared Photodetectors with High Gain. Nano Lett. 2016, 16, 4648-4655. [CrossRef]

22. Long, M.; Liu, E.; Wang, P.; Gao, A.; Xia, H.; Luo, W.; Wang, B.; Zeng, J.; Fu, Y.; Xu, K.; et al. Broadband Photovoltaic Detectors Based on an Atomically Thin Heterostructure. Nano Lett. 2016, 16, 2254-2259. [CrossRef]

23. Zhu, Y.; Li, Z.; Zhang, L.; Wang, B.; Luo, Z.; Long, J.; Yang, J.; Fu, L.; Lu, Y. High-Efficiency Monolayer Molybdenum Ditelluride Light-Emitting Diode and Photodetector. ACS Appl. Mater. Interfaces 2018, 10, 43291-43298. [CrossRef] 
24. Logeeswaran, V.J.; Oh, J.; Nayak, A.P.; Katzenmeyer, A.M.; Gilchrist, K.H.; Grego, S.; Kobayashi, N.P.; Wang, S.-Y.; Talin, A.A.; Dhar, N.K.; et al. A perspective on Nanowire Photodetectors: Current Status, Future Challenges, and Opportunities. IEEE J. Sel. Top. Quantum Electron. 2011, 17, 1002-1032.

25. Krogstrup, P.; Jørgensen, H.I.; Heiss, M.; Demichel, O.; Holm, J.V.; Aagesen, M.; Nygard, J.; i Morral, A.F. Single-nanowire solar cells beyond the Shockley-Queisser limit. Nat. Photonics 2013, 7, 306-310. [CrossRef]

26. Åberg, I.; Vescovi, G.; Asoli, D.; Naseem, U.; Gilboy, J.P.; Sundvall, C.; Dahlgren, A.; Svensson, K.E.; Anttu, N.; Björk, M.T.; et al. A GaAs Nanowire Array Solar Cell With 15.3\% Efficiency at 1 Sun. IEEE J. Photovolt. 2016, 6, 185-190. [CrossRef]

27. Li, Z.; Yang, I.; Li, L.; Gao, Q.; Chong, J.S.; Li, Z.; Lockrey, M.N.; Tan, H.H.; Jagadish, C.; Fu, L. Reducing Zn diffusion in single axial junction InP nanowire solar cells for improved performance. Prog. Nat. Sci. Mater. 2018, 28, 178-182. [CrossRef]

28. Zhang, G.; Li, Z.; Yuan, X.; Wang, F.; Fu, L.; Zhuang, Z.; Ren, F.-F.; Liu, B.; Zhang, R.; Tan, H.H. Single nanowire green InGaN/GaN light emitting diodes. Nanotechnology 2016, 27, 435205. [CrossRef] [PubMed]

29. Chu, S.; Wang, G.; Zhou, W.; Lin, Y.; Chernyak, L.; Zhao, J.; Kong, J.; Li, L.; Ren, J.; Liu, J. Electrically pumped waveguide lasing from ZnO nanowires. Nat. Nanotechnol. 2011, 6, 506-510. [CrossRef] [PubMed]

30. Saxena, D.; Mokkapati, S.; Parkinson, P.; Jiang, N.; Gao, Q.; Tan, H.H.; Jagadish, C. Optically pumped room-temperature GaAs nanowire lasers. Nat. Photonics 2013, 7, 963-968. [CrossRef]

31. Li, K.H.; Liu, X.; Wang, Q.; Zhao, S.; Mi, Z. Ultralow-threshold electrically injected AlGaN nanowire ultraviolet lasers on Si operating at low temperature. Nat. Nanotechnol. 2015, 10, 140-144. [CrossRef]

32. Soci, C.; Zhang, A.; Bao, X.-Y.; Kim, H.; Lo, Y.; Wang, D. Nanowire Photodetectors. J. Nanosci. Nanotechnol. 2010, 10, 1430-1449. [CrossRef]

33. Li, Z.; Tan, H.H.; Jagadish, C.; Fu, L. III-V Semiconductor Single Nanowire Solar Cells: A Review. Adv. Mater. Technol. 2018, 3, 1800005. [CrossRef]

34. Sun, J.; Han, M.; Gu, Y.; Yang, Z.X.; Zeng, H. Recent Advances in Group III-V Nanowire Infrared Detectors. Adv. Opt. Mater. 2018, 6, 1800256. [CrossRef]

35. Zheng, D.; Wang, J.; Hu, W.; Liao, L.; Fang, H.; Guo, N.; Wang, P.; Gong, F.; Wang, X.; Fan, Z.; et al. When Nanowires Meet Ultrahigh Ferroelectric Field-High-Performance Full-Depleted Nanowire Photodetectors. Nano Lett. 2016, 16, 2548-2555. [CrossRef] [PubMed]

36. Alexander-Webber, J.A.; Groschner, C.K.; Sagade, A.A.; Tainter, G.; Gonzalez-Zalba, M.F.; Di Pietro, R.; Wong-Leung, J.; Tan, H.H.; Jagadish, C.; Hofmann, S.; et al. Engineering the Photoresponse of InAs Nanowires. ACS Appl. Mater. Interfaces 2017, 9, 43993-44000. [CrossRef] [PubMed]

37. Han, Y.; Fu, M.; Tang, Z.; Zheng, X.; Ji, X.; Wang, X.; Lin, W.; Yang, T.; Chen, Q. Switching from Negative to Positive Photoconductivity toward Intrinsic Photoelectric Response in InAs Nanowire. ACS Appl. Mater. Interfaces 2017, 9, 2867-2874. [CrossRef] [PubMed]

38. Thunich, S.; Prechtel, L.; Spirkoska, D.; Abstreiter, G.; Fontcuberta i Morral, A.; Holleitner, A.W. Photocurrent and photoconductance properties of a GaAs nanowire. Appl. Phys. Lett. 2009, 95, 083111. [CrossRef]

39. Fang, H.; Hu, W.; Wang, P.; Guo, N.; Luo, W.; Zheng, D.; Gong, F.; Luo, M.; Tian, H.; Zhang, X.; et al. Visible Light-Assisted High-Performance Mid-Infrared Photodetectors Based on Single InAs Nanowire. Nano Lett. 2016, 16, 6416-6424. [CrossRef] [PubMed]

40. Yan, X.; Li, B.; Wu, Y.; Zhang, X.; Ren, X. A single crystalline InP nanowire photodetector. Appl. Phys. Lett. 2016, 109, 053109. [CrossRef]

41. Chen, H.; Sun, X.; Lai, K.W.C.; Meyyappan, M.; Xi, N. Infrared detection using an InSb nanowire. In Proceedings of the IEEE Nanotechnology Materials and Devices Conference, Traverse City, MI, USA, 2-5 June 2009; pp. 212-216.

42. Ma, L.; Hu, W.; Zhang, Q.; Ren, P.; Zhuang, X.; Zhou, H.; Xu, J.; Li, H.; Shan, Z.; Wang, X.; et al. Room-Temperature Near-Infrared Photodetectors Based on Single Heterojunction Nanowires. Nano Lett. 2014, 14, 694-698. [CrossRef]

43. Brenneis, A.; Overbeck, J.; Treu, J.; Hertenberger, S.; Morkötter, S.; Döblinger, M.; Finley, J.J.; Abstreiter, G.; Koblmüller, G.; Holleitner, A.W. Photocurrents in a Single InAs Nanowire/Silicon Heterojunction. ACS Nano 2015, 9, 9849-9858. [CrossRef]

44. Dai, X.; Zhang, S.; Wang, Z.; Adamo, G.; Liu, H.; Huang, Y.; Couteau, C.; Soci, C. GaAs/AlGaAs Nanowire Photodetector. Nano Lett. 2014, 14, 2688-2693. [CrossRef] 
45. Miao, J.; Hu, W.; Guo, N.; Lu, Z.; Liu, X.; Liao, L.; Chen, P.; Jiang, T.; Wu, S.; Ho, J.C.; et al. High-Responsivity Graphene/InAs Nanowire Heterojunction Near-Infrared Photodetectors with Distinct Photocurrent On/Off Ratios. Small 2015, 11, 936-942. [CrossRef]

46. Li, H.; Alradhi, H.; Jin, Z.; Anyebe, E.A.; Sanchez, A.M.; Linhart, W.M.; Kudrawiec, R.; Fang, H.; Wang, Z.; $\mathrm{Hu}, \mathrm{W}$.; et al. Novel Type-II InAs/AlSb Core-Shell Nanowires and Their Enhanced Negative Photocurrent for Efficient Photodetection. Adv. Funct. Mater. 2018, 28, 1705382. [CrossRef]

47. Guo, N.; Hu, W.; Liao, L.; Yip, S.; Ho, J.C.; Miao, J.; Zhang, Z.; Zou, J.; Jiang, T.; Wu, S.; et al. Anomalous and highly efficient InAs nanowire phototransistors based on majority carrier transport at room temperature. Adv. Mater. 2014, 26, 8203-8209. [CrossRef] [PubMed]

48. Casadei, A.; Llado, E.A.; Amaduzzi, F.; Russo-Averchi, E.; Rüffer, D.; Heiss, M.; Dal Negro, L.; Fontcuberta i Morral, A. Polarization response of nanowires à la carte. Sci. Rep. 2015, 5, 7651. [CrossRef]

49. Hobbs, R.G.; Petkov, N.; Holmes, J.D. Semiconductor Nanowire Fabrication by Bottom-Up and Top-Down Paradigms. Chem. Mater. 2012, 24, 1975-1991. [CrossRef]

50. Shen, L.; Pun, E.Y.B.; Ho, J.C. Recent developments in III-V semiconducting nanowires for high-performance photodetectors. Mater. Chem. Front. 2017, 1, 630-645. [CrossRef]

51. Costner, E.A.; Lin, M.W.; Jen, W.-L.; Willson, C.G. Nanoimprint lithography materials development for semiconductor device fabrication. Annu. Rev. Mater. Res. 2009, 39, 155-180. [CrossRef]

52. Gao, Q.; Dubrovskii, V.G.; Caroff, P.; Wong-Leung, J.; Li, L.; Guo, Y.; Fu, L.; Tan, H.H.; Jagadish, C. Simultaneous Selective-Area and Vapor-Liquid-Solid Growth of InP Nanowire Arrays. Nano Lett. 2016, 16, 4361-4367. [CrossRef]

53. Hou, J.J.; Han, N.; Wang, F.; Xiu, F.; Yip, S.; Hui, A.T.; Hung, T.; Ho, J.C. Synthesis and Characterizations of Ternary InGaAs Nanowires by a Two-Step Growth Method for High-Performance Electronic Devices. ACS Nano 2012, 6, 3624-3630. [CrossRef]

54. Colombo, C.; Spirkoska, D.; Frimmer, M.; Abstreiter, G.; Fontcuberta i Morral, A. Ga-assisted catalyst-free growth mechanism of GaAs nanowires by molecular beam epitaxy. Phys. Rev. B 2008, 77, 155326. [CrossRef]

55. Morales, A.M.; Lieber, C.M. A Laser Ablation Method for the Synthesis of Crystalline Semiconductor Nanowires. Science 1998, 279, 208-211. [CrossRef]

56. Mårtensson, T.; Carlberg, P.; Borgström, M.; Montelius, L.; Seifert, W.; Samuelson, L. Nanowire Arrays Defined by Nanoimprint Lithography. Nano Lett. 2004, 4, 699-702. [CrossRef]

57. Tomioka, K.; Tanaka, T.; Hara, S.; Hiruma, K.; Fukui, T. III-V Nanowires on Si Substrate: Selective-Area Growth and Device Applications. IEEE J. Sel. Top. Quantum Electron. 2011, 17, 1112-1129. [CrossRef]

58. Jiang, N.; Parkinson, P.; Gao, Q.; Breuer, S.; Tan, H.H.; Wong-Leung, J.; Jagadish, C. Long minority carrier lifetime in Au-catalyzed GaAs/ $\mathrm{Al}_{x} \mathrm{Ga}_{1-x}$ As core-shell nanowires. Appl. Phys. Lett. 2012, 101, 023111. [CrossRef]

59. Persson, A.I.; Larsson, M.W.; Stenström, S.; Ohlsson, B.J.; Samuelson, L.; Wallenberg, L.R. Solid-phase diffusion mechanism for GaAs nanowire growth. Nat. Mater. 2004, 3, 677-681. [CrossRef] [PubMed]

60. Huh, J.; Yun, H.; Kim, D.-C.; Munshi, A.M.; Dheeraj, D.L.; Kauko, H.; van Helvoort, A.T.J.; Lee, S.; Fimland, B.-O.; Weman, H. Rectifying Single GaAsSb Nanowire Devices Based on Self-Induced Compositional Gradients. Nano Lett. 2015, 15, 3709-3715. [CrossRef]

61. Zhang, C.; Miao, X.; Mohseni, P.K.; Choi, W.; Li, X. Site-Controlled VLS Growth of Planar Nanowires: Yield and Mechanism. Nano Lett. 2014, 14, 6836-6841. [CrossRef]

62. Wang, F.; Gao, Q.; Peng, K.; Li, Z.; Li, Z.; Guo, Y.; Fu, L.; Smith, L.M.; Tan, H.H.; Jagadish, C. Spatially Resolved Doping Concentration and Nonradiative Lifetime Profiles in Single Si-Doped InP Nanowires Using Photoluminescence Mapping. Nano Lett. 2015, 15, 3017-3023. [CrossRef]

63. Peng, K.; Parkinson, P.; Gao, Q.; Boland, J.L.; Li, Z.; Wang, F.; Mokkapati, S.; Fu, L.; Johnston, M.B.; Tan, H.H.; et al. Single $\mathrm{n}^{+}-\mathrm{i}-\mathrm{n}^{+}$InP nanowires for highly sensitive terahertz detection. Nanotechnology 2017, 28, 125202. [CrossRef]

64. Zhang, R.-Q.; Lifshitz, Y.; Lee, S.-T. Oxide-Assisted Growth of Semiconducting Nanowires. Adv. Mater. 2003, 15, 635-640. [CrossRef]

65. Shimizu, T.; Xie, T.; Nishikawa, J.; Shingubara, S.; Senz, S.; Gösele, U. Synthesis of Vertical High-Density Epitaxial Si (100) Nanowire Arrays on a Si (100) Substrate Using an Anodic Aluminum Oxide Template. Adv. Mater. 2007, 19, 917-920. [CrossRef] 
66. Xia, H.; Lu, Z.-Y.; Li, T.-X.; Parkinson, P.; Liao, Z.-M.; Liu, F.-H.; Lu, W.; Hu, W.-D.; Chen, P.-P.; Xu, H.-Y.; et al. Distinct Photocurrent Response of Individual GaAs Nanowires Induced by n-Type Doping. ACS Nano 2012, 6, 6005-6013. [CrossRef] [PubMed]

67. Han, S.; Jin, W.; Zhang, D.; Tang, T.; Li, C.; Liu, X.; Liu, Z.; Lei, B.; Zhou, C. Photoconduction studies on GaN nanowire transistors under UV and polarized UV illumination. Chem. Phys. Lett. 2004, 389, 176-180. [CrossRef]

68. Chen, R.-S.; Chen, H.-Y.; Lu, C.-Y.; Chen, K.-H.; Chen, C.-P.; Chen, L.-C.; Yang, Y.-J. Ultrahigh photocurrent gain in $m$-axial GaN nanowires. Appl. Phys. Lett. 2007, 91, 223106. [CrossRef]

69. Yang, Z.; Albrow-Owen, T.; Cui, H.; Alexander-Webber, J.; Gu, F.; Wang, X.; Wu, T.-C.; Zhuge, M.; Williams, C.; Wang, P.; et al. Single-nanowire spectrometers. Science 2019, 365, 1017-1020. [CrossRef] [PubMed]

70. Cao, L.; White, J.S.; Park, J.-S.; Schuller, J.A.; Clemens, B.M.; Brongersma, M.L. Engineering light absorption in semiconductor nanowire devices. Nat. Mater. 2009, 8, 643-647. [CrossRef] [PubMed]

71. Gallo, E.M.; Chen, G.; Currie, M.; McGuckin, T.; Prete, P.; Lovergine, N.; Nabet, B.; Spanier, J.E. Picosecond response times in GaAs/AlGaAs core/shell nanowire-based photodetectors. Appl. Phys. Lett. 2011, 98, 241113. [CrossRef]

72. Logeeswaran, V.J.; Sarkar, A.; Islam, M.S.; Kobayashi, N.P.; Straznicky, J.; Li, X.; Wu, W.; Mathai, S.; Tan, M.R.T.; Wang, S.-Y.; et al. A 14-ps full width at half maximum high-speed photoconductor fabricated with intersecting InP nanowires on an amorphous surface. Appl. Phys. A 2008, 91, 1-5. [CrossRef]

73. Luo, T.; Liang, B.; Liu, Z.; Xie, X.; Lou, Z.; Shen, G. Single-GaSb-nanowire-based room temperature photodetectors with broad spectral response. Sci. Bull. 2015, 60, 101-108. [CrossRef]

74. Kuo, C.-H.; Wu, J.-M.; Lin, S.-J.; Chang, W.-C. High sensitivity of middle-wavelength infrared photodetectors based on an individual InSb nanowire. Nanoscale Res. Lett. 2013, 8, 327. [CrossRef]

75. Yuan, X.; Li, L.; Li, Z.; Wang, F.; Wang, N.; Fu, L.; He, J.; Tan, H.H.; Jagadish, C. Unexpected benefits of stacking faults on electronic structure and optical emission in wurtzite GaAs/GaInP core/shell nanowires. Nanoscale 2019, 11, 9207-9215. [CrossRef]

76. Li, Z.; Yuan, X.; Gao, Q.; Yang, I.; Li, L.; Caroff, P.; Allen, M.S.; Allen, J.; Tan, H.H.; Jagadish, C.; et al. In situ passivation of GaAsSb nanowires for enhanced infrared photoresponse. Nanotechnology 2020, in press. [CrossRef] [PubMed]

77. Tan, H.; Fan, C.; Ma, L.; Zhang, X.; Fan, P.; Yang, Y.; Hu, W.; Zhou, H.; Zhuang, X.; Zhu, X.; et al. Single-Crystalline InGaAs Nanowires for Room-Temperature High-Performance Near-Infrared Photodetectors. Nano Micro Lett. 2016, 8, 29-35. [CrossRef] [PubMed]

78. Ren, P.; Hu, W.; Zhang, Q.; Zhu, X.; Zhuang, X.; Ma, L.; Fan, X.; Zhou, H.; Liao, L.; Duan, X.; et al. Band-Selective Infrared Photodetectors with Complete-Composition-Range InAs $\mathrm{P}_{1-x}$ Alloy Nanowires. Adv. Mater. 2014, 26, 7444-7449. [CrossRef] [PubMed]

79. Wang, P.J.; Wessels, B.W. Heteroepitaxial growth of high mobility InAsP from the vapor phase. Appl. Phys. Lett. 1984, 44, 766-768. [CrossRef]

80. Yang, Y.; Peng, X.; Kim, H.-S.; Kim, T.; Jeon, S.; Kang, H.K.; Choi, W.; Song, J.; Doh, Y.-J.; Yu, D. Hot Carrier Trapping Induced Negative Photoconductance in InAs Nanowires toward Novel Nonvolatile Memory. Nano Lett. 2015, 15, 5875-5882. [CrossRef] [PubMed]

81. Zhang, X.; Li, Z.; Yao, X.; Huang, H.; Wei, D.; Zhou, C.; Tang, Z.; Yuan, X.; Chen, P.; Hu, W.; et al. Light-Induced Positive and Negative Photoconductances of InAs Nanowires toward Rewritable Nonvolatile Memory. ACS Appl. Electron. Mater. 2019, 1, 1825-1831. [CrossRef]

82. Zhang, X.; Huang, H.; Yao, X.; Li, Z.; Zhou, C.; Zhang, X.; Chen, P.; Fu, L.; Zhou, X.; Wang, J.; et al. Ultrasensitive Mid-Wavelength Infrared Photodetection Based on Single InAs Nanowire. ACS Nano 2019, 13, 3492-3499. [CrossRef]

83. Vitiello, M.S.; Coquillat, D.; Viti, L.; Ercolani, D.; Teppe, F.; Pitanti, A.; Beltram, F.; Sorba, L.; Knap, W.; Tredicucci, A. Room-Temperature Terahertz Detectors Based on Semiconductor Nanowire Field-Effect Transistors. Nano Lett. 2012, 12, 96-101. [CrossRef]

84. Vitiello, M.S.; Viti, L.; Romeo, L.; Ercolani, D.; Scalari, G.; Faist, J.; Beltram, F.; Sorba, L.; Tredicucci, A. Semiconductor nanowires for highly sensitive, room-temperature detection of terahertz quantum cascade laser emission. Appl. Phys. Lett. 2012, 100, 241101. [CrossRef] 
85. Romeo, L.; Coquillat, D.; Pea, M.; Ercolani, D.; Beltram, F.; Sorba, L.; Knap, W.; Tredicucci, A.; Vitiello, M.S. Nanowire-based field effect transistors for terahertz detection and imaging systems. Nanotechnology 2013, 24, 214005. [CrossRef]

86. Ravaro, M.; Locatelli, M.; Viti, L.; Ercolani, D.; Consolino, L.; Bartalini, S.; Sorba, L.; Vitiello, M.S.; de Natale, P. Detection of a $2.8 \mathrm{THz}$ quantum cascade laser with a semiconductor nanowire field-effect transistor coupled to a bow-tie antenna. Appl. Phys. Lett. 2014, 104, 083116. [CrossRef]

87. Sze, S.M.; Ng, K.K. Physics of Semiconductor Devices; John Wiley \& Sons: Hoboken, NJ, USA, 2006.

88. Wang, H. High gain single GaAs nanowire photodetector. Appl. Phys. Lett. 2013, 103, 093101. [CrossRef]

89. Persano, A.; Taurino, A.; Prete, P.; Lovergine, N.; Nabet, B.; Cola, A. Photocurrent properties of single GaAs/AlGaAs core-shell nanowires with Schottky contacts. Nanotechnology 2012, 23, 465701. [CrossRef] [PubMed]

90. Wang, X.; Pan, D.; Han, Y.; Sun, M.; Zhao, J.; Chen, Q. Vis-IR Wide-Spectrum Photodetector at Room Temperature Based on p-n Junction-Type $\mathrm{GaAs}_{1-x} \mathrm{Sb}_{x} / \mathrm{InAs}$ Core-Shell Nanowire. ACS Appl. Mater. Interfaces 2019, 11, 38973-38981. [CrossRef]

91. Chuang, L.C.; Sedgwick, F.G.; Chen, R.; Ko, W.S.; Moewe, M.; Ng, K.W.; Tran, T.-T.D.; Chang-Hasnain, C. GaAs-Based Nanoneedle Light Emitting Diode and Avalanche Photodiode Monolithically Integrated on a Silicon Substrate. Nano Lett. 2010, 11, 385-390. [CrossRef]

92. Senanayake, P.; Hung, C.-H.; Farrell, A.; Ramirez, D.A.; Shapiro, J.; Li, C.-K.; Wu, Y.-R.; Hayat, M.M.; Huffaker, D.L. Thin 3D Multiplication Regions in Plasmonically Enhanced Nanopillar Avalanche Detectors. Nano Lett. 2012, 12, 6448-6452. [CrossRef]

93. Farrell, A.C.; Meng, X.; Ren, D.; Kim, H.; Senanayake, P.; Hsieh, N.Y.; Rong, Z.; Chang, T.-Y.; Azizur-Rahman, K.M.; Huffaker, D.L. InGaAs-GaAs Nanowire Avalanche Photodiodes Toward Single-Photon Detection in Free-Running Mode. Nano Lett. 2018, 19, 582-590. [CrossRef]

94. Peng, K.; Parkinson, P.; Fu, L.; Gao, Q.; Jiang, N.; Guo, Y.-N.; Wang, F.; Joyce, H.J.; Boland, J.L.; Tan, H.H.; et al. Single Nanowire Photoconductive Terahertz Detectors. Nano Lett. 2015, 15, 206-210. [CrossRef]

95. Peng, K.; Parkinson, P.; Fu, L.; Gao, Q.; Boland, J.; Guo, Y.-N.; Jian, N.; Tan, H.H.; Johnston, M.B.; Jagadish, C. Distinguishing cap and core contributions to the photoconductive terahertz response of single GaAs based core-shell-cap nanowire detectors. Lith. J. Phys. 2018, 58, 15-23. [CrossRef]

96. Peng, K.; Parkinson, P.; Boland, J.L.; Gao, Q.; Wenas, Y.C.; Davies, C.L.; Li, Z.; Fu, L.; Johnston, M.B.; Tan, H.H.; et al. Broadband Phase-Sensitive Single InP Nanowire Photoconductive Terahertz Detectors. Nano Lett. 2016, 16, 4925-4931. [CrossRef]

97. Senanayake, P.; Hung, C.-H.; Shapiro, J.; Lin, A.; Liang, B.; Williams, B.S.; Huffaker, D.L. Surface Plasmon-Enhanced Nanopillar Photodetectors. Nano Lett. 2011, 11, 5279-5283. [CrossRef] [PubMed]

98. Maharjan, A.; Pemasiri, K.; Kumar, P.; Wade, A.; Smith, L.M.; Jackson, H.E.; Yarrison-Rice, J.M.; Kogan, A.; Paiman, S.; Gao, Q.; et al. Room temperature photocurrent spectroscopy of single zincblende and wurtzite InP nanowires. Appl. Phys. Lett. 2009, 94, 193115. [CrossRef]

99. Liu, Z.; Luo, T.; Liang, B.; Chen, G.; Yu, G.; Xie, X.; Chen, D.; Shen, G. High-detectivity InAs nanowire photodetectors with spectral response from ultraviolet to near-infrared. Nano Res. 2013, 6, 775-783. [CrossRef]

100. Khan, M.I.; Wang, X.; Jing, X.; Bozhilov, K.N.; Ozkan, C.S. Study of a Single InSb Nanowire Fabricated via DC Electrodeposition in Porous Templates. J. Nanosci. Nanotechnol. 2009, 9, 2639-2644. [CrossRef] [PubMed]

101. Ma, L.; Zhang, X.; Li, H.; Tan, H.; Yang, Y.; Xu, Y.; Hu, W.; Zhu, X.; Zhuang, X.; Pan, A. Bandgap-engineered GaAsSb alloy nanowires for near-infrared photodetection at $1.31 \mu \mathrm{m}$. Semicond. Sci. Technol. 2015, 30, 105033. [CrossRef]

102. Duan, X.; Huang, Y.; Cui, Y.; Wang, J.; Lieber, C.M. Indium phosphide nanowires as building blocks for nanoscale electronic and optoelectronic devices. Nature 2001, 409, 66-69. [CrossRef]

103. Pauzauskie, P.J.; Radenovic, A.; Trepagnier, E.; Shroff, H.; Yang, P.; Liphardt, J. Optical trapping and integration of semiconductor nanowire assemblies in water. Nat. Mater. 2006, 5, 97-101. [CrossRef]

104. Smith, P.A.; Nordquist, C.D.; Jackson, T.N.; Mayer, T.S.; Martin, B.R.; Mbindyo, J.; Mallouk, T.E. Electric-field assisted assembly and alignment of metallic nanowires. Appl. Phys. Lett. 2000, 77, 1399-1401. [CrossRef]

105. Hur, S.-H.; Park, O.O.; Rogers, J.A. Extreme bendability of single-walled carbon nanotube networks transferred from high-temperature growth substrates to plastic and their use in thin-film transistors. Appl. Phys. Lett. 2005, 86, 243502. [CrossRef] 
106. Jin, S.; Whang, D.; McAlpine, M.C.; Friedman, R.S.; Wu, Y.; Lieber, C.M. Scalable Interconnection and Integration of Nanowire Devices without Registration. Nano Lett. 2004, 4, 915-919. [CrossRef]

107. Guilhabert, B.; Hurtado, A.; Jevtics, D.; Gao, Q.; Tan, H.H.; Jagadish, C.; Dawson, M.D. Transfer Printing of Semiconductor Nanowires with Lasing Emission for Controllable Nanophotonic Device Fabrication. ACS Nano 2016, 10, 3951-3958. [CrossRef]

108. Jevtics, D.; Hurtado, A.; Guilhabert, B.; McPhillimy, J.; Cantarella, G.; Gao, Q.; Tan, H.H.; Jagadish, C.; Strain, M.J.; Dawson, M.D. Integration of Semiconductor Nanowire Lasers with Polymeric Waveguide Devices on a Mechanically Flexible Substrate. Nano Lett. 2017, 17, 5990-5994. [CrossRef] [PubMed]

109. Fan, Z.; Ho, J.C.; Jacobson, Z.A.; Yerushalmi, R.; Alley, R.L.; Razavi, H.; Javey, A. Wafer-Scale Assembly of Highly Ordered Semiconductor Nanowire Arrays by Contact Printing. Nano Lett. 2008, 8, 20-25. [CrossRef] [PubMed]

110. Knight, M.W.; Sobhani, H.; Nordlander, P.; Halas, N.J. Photodetection with active optical antennas. Science 2011, 332, 702-704. [CrossRef] [PubMed]

111. Karimi, M.; Heurlin, M.; Limpert, S.; Jain, V.; Zeng, X.; Geijselaers, I.; Nowzari, A.; Fu, Y.; Samuelson, L.; Linke, H.; et al. Intersubband Quantum Disc-in-Nanowire Photodetectors with Normal-Incidence Response in the Long-Wavelength Infrared. Nano Lett. 2018, 18, 365-372. [CrossRef] [PubMed]

(C) 2020 by the authors. Licensee MDPI, Basel, Switzerland. This article is an open access article distributed under the terms and conditions of the Creative Commons Attribution (CC BY) license (http://creativecommons.org/licenses/by/4.0/). 